\title{
Article \\ On-line Detection and Classification of PMSM Stator Winding Faults Based on Stator Current Symmetrical Components Analysis and the KNN Algorithm
}

\author{
Przemyslaw Pietrzak (D) and Marcin Wolkiewicz *(D) \\ Department of Electrical Machines, Drives and Measurements, Wroclaw University of Science and Technology, \\ Wybrzeze Wyspianskiego 27, 50-370 Wroclaw, Poland; przemyslaw.pietrzak@pwr.edu.pl \\ * Correspondence: marcin.wolkiewicz@pwr.edu.pl
}

Citation: Pietrzak, P.; Wolkiewicz, M. On-line Detection and Classification of PMSM Stator Winding Faults Based on Stator Current Symmetrical Components Analysis and the KNN Algorithm. Electronics 2021, 10, 1786. https://doi.org/10.3390/

electronics10151786

Academic Editor: Imre J. Rudas

Received: 23 June 2021

Accepted: 23 July 2021

Published: 26 July 2021

Publisher's Note: MDPI stays neutral with regard to jurisdictional claims in published maps and institutional affiliations.

Copyright: (c) 2021 by the authors. Licensee MDPI, Basel, Switzerland. This article is an open access article distributed under the terms and conditions of the Creative Commons Attribution (CC BY) license (https:// creativecommons.org/licenses/by/ $4.0 /)$.

\begin{abstract}
The significant advantages of permanent magnet synchronous motors, such as very good dynamic properties, high efficiency and power density, have led to their frequent use in many drive systems today. However, like other types of electric motors, they are exposed to various types of faults, including stator winding faults. Stator winding faults are mainly inter-turn short circuits and are among the most common faults in electric motors. In this paper, the possibility of using the spectral analysis of symmetrical current components to extract fault symptoms and the machinelearning-based K-Nearest Neighbors (KNN) algorithm for the detection and classification of the PMSM stator winding fault is presented. The impact of the key parameters of this classifier on the effectiveness of stator winding fault detection and classification is presented and discussed in detail, which has not been researched in the literature so far. The proposed solution was verified experimentally using a $2.5 \mathrm{~kW}$ PMSM, the construction of which was specially prepared for carrying out controlled inter-turn short circuits.
\end{abstract}

Keywords: fault diagnosis; permanent magnet synchronous motor; inter-turn short circuit; symmetrical components; K-nearest neighbors; machine learning

\section{Introduction}

The popularity of Permanent Magnet Synchronous Motors (PMSMs) has continued to increase in recent years. This is due to the fact that they are characterized by very good properties such as very high efficiency, high reliability, control of a wide range of rotational speeds and a low rotor moment of inertia [1,2]. Because of this, PMSMs are largely applied to automotive motors, home appliances and other industrial automatic control applications, gradually replacing induction motors $[3,4]$.

In general, electric motors, even when operated under normal conditions, are exposed to various types of damages. The most common faults of electric machines are bearing $(41 \%)$, stator (36\%) and rotor (9\%) faults, whereas $14 \%$ correspond to other failures [5]. This also applies to highly efficient and durable PMSMs. The stator winding fault is one of the most common faults of PMSMs. Apart from the wrong connection of windings, stator faults include various types of short circuits (Figure 1): inter-turn short circuits, short circuits between the coils in one phase, phase-to-phase short circuits, phase-to-ground short circuits and open circuits (breaks in phases) [6]. However, the most common situation is that a stator winding fault starts with an inter-turn short circuit, which is very difficult to detect at an early stage.

Inter-turn short circuits are mainly caused by stator winding insulation damage due to electrical stresses, mechanical stresses and overload [7]. This type of failure is very destructive. An imperceptible short circuit between adjacent turns can spread very quickly over the whole winding, causing the main short circuit and leading to an emergency stop of the drive system [8]. This spreading is the result of a large circulating fault current 
induced in the faulted loop, which is associated with a significant temperature increase in a given part of the winding, rapidly degrading the winding insulation [9]. Moreover, stator winding faults can have a negative impact on rotor permanent magnets. Due to the high temperature in the shorted part of the stator winding and magnetic field value amplified to greater than magnet coercivity, partial or complete irreversible demagnetization may occur [10].

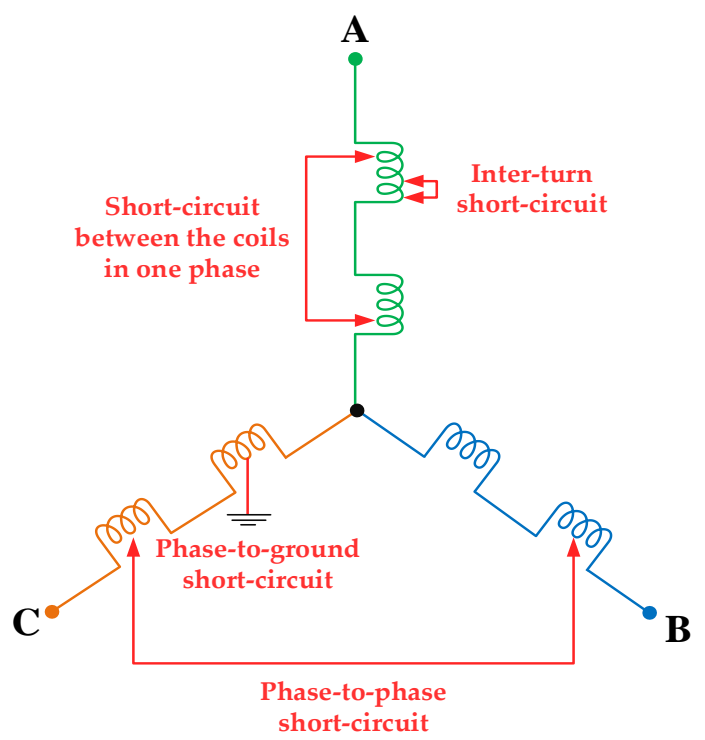

Figure 1. PMSM stator winding short-circuit types.

Taking into account the aforementioned increasing popularity of PMSMs, with the nature of stator winding faults and the constant pursuit of the most reliable solutions in mind, new methods of detecting and classifying this type of failure with the highest possible efficiency and at an early stage are still being sought. The development of such methods may prevent the complete and costly failure of the drive system. Emergency downtimes may also cause long delays in the industrial process. Moreover, an effective diagnostic system guarantees safe operation and extends the lifetime of the motor [11,12].

There are many methods used for electric motor fault detection, including PMSMs [13-17]. Diagnostic methods are mostly based on the processed signal. Signal processing allows for the extraction of fault features [18]. Mathematical apparatuses used for symptom extraction from the stator phase current signal include those that perform frequency and time-frequency domain analysis. The phase current signal is the most commonly used signal in the process of stator winding fault detection [19]. One of the most popular fault diagnosis techniques based on motor current analysis is Motor Current Signature Analysis (MCSA). Fast Fourier Transform (FFT) is also a powerful and simple MCSA technique [20]. The effectiveness of the application of this method for the detection of interturn short circuits was confirmed among others in [8] and [21]. The group of methods that performs time-frequency domain analysis is dominated by Continuous Wavelet Transform (CWT) [22,23], Discrete Wavelet Transform (DWT) [24,25], Short-Time Fourier Transform (STFT) [26] and Hilbert-Huang Transform [27]. Signal processing methods based on HighOrder Transforms (HOTs) are also used in PMSM stator winding fault diagnostics. HOTs that have been applied in diagnostics are bispectrum [28,29], MUltiple Signal Classification (MUSIC) [30] and Estimation of Signal Parameters via Rotational Invariance Techniques (ESPRIT) [31]. In addition to the processing of the stator phase current signal, attempts have also been made to use the symmetrical components of the stator current for stator winding fault detection of induction motors [32] and PMSMs [33].

Except for the extraction of fault symptoms from which the signal is carrying diagnostic information, it is extremely important to develop an algorithm that infers the condition of the motor and classifies the degree of damage. In recent years, this function has been 
entrusted more and more often to fault classifiers that are based on Machine Learning (ML) algorithms. These algorithms are used in knowledge-based approaches, and they are constantly being improved. Therefore, it seems to be a promising research direction in the field of fault diagnostics [34].

ML has become a very popular technique and is an inherent part of the Artificial Intelligence (AI) field. Subcategories of classic ML algorithms, such as Decision Tree (DT), Support Vector Machine (SVM) and K-Nearest Neighbors (KNN), are algorithms whose operation is inspired by the human brain operation principle-Artificial Neural Networks (ANNs) and Deep Neural Networks (DNN).

The usage of the above-mentioned methods can minimize human participation in fault diagnosis and help in automating this process. Therefore, the usage of selected MLbased classifiers, shallow and deep neural networks, has been verified to detect various types of electric motor faults [10,35-45]. Taking into account an electric motor fault other than mechanical failure, there are still very few scientific papers in which the usage of simple machine learning algorithms to detect PMSM stator winding faults is presented, especially taking into account the analysis of the key parameter selection of fault classifiers on their effectiveness.

It is also important that due to the increasing requirements for the reliability of drive systems, classical diagnostic methods are not sufficient. In order to meet these requirements, nowadays, it is recommended to use intelligent diagnostic methods. An extensive review of AI-based fault diagnostic methods for PMSMs is presented in [46]. The authors discussed methods that use artificial knowledge technology such as neural networks, expert systems and fuzzy logic to realize complex motor fault detection and condition monitoring. Moreover, the idea of Industry 4.0, the popularity of which has increased rapidly in recent years, is also closely connected with the condition monitoring of drives systems or even whole industrial processes. More and more often, the solutions ensuring the wireless transmission of information about machine conditions and other promising smart approaches are being proposed [47-49], as well as those that demonstrate an advanced embedded online monitoring algorithm [50].

The main goal of this article is inter-turn short-circuit detection and classification in PMSM stator windings using the spectral analysis of symmetrical current components to extract the fault symptoms and a simple ML-based classifier (KNN). Furthermore, the impact of the key parameters of this classifier on the effectiveness of stator winding fault detection and classification during off-line and on-line verification is presented and discussed in detail. The efficiency of the KNN algorithm to detect various faults of induction motors has been proven in recent years among others in [34,51-53]. Nonetheless, there is a visible gap in current research with regard to the usage of simple AI-based algorithms such as KNN to PMSM stator winding fault detection and classification. In particular, there is a lack of solutions that allow for the detection of this type of fault at a very early stage, with just one shorted turn in the stator winding coil. Widely discussed in the diagnostic literature, artificial neural networks require a long training time, while there are relatively few solutions guaranteeing both a short training time and effective classification with a resolution to one turn.

The novelty of the solution presented in this paper results from:

- A combination of symmetrical current component analysis and a simple machine learning algorithm for detecting inter-turn short circuits in PMSM stator windings, along with a proposition of an on-line diagnostic system based on LabVIEW and MATLAB environments;

- Proposing a stator winding fault classifier $(\mathrm{KNN})$, the learning time of which is much shorter than in the case of artificial neural network based classifiers, widely described in the literature;

- A detailed examination of the impact of key parameter (hyper-parameters) changes of the tested classifier on its effectiveness and a proposal of the best solution, 
- The proposal of a solution that allows the detection of failure at a very early stage, with one shorted turn in a stator winding and under various motor operating conditions.

The article is divided into seven sections. After this introduction, Section 2 discusses the proposed KNN-based fault classifiers. Successively, the extraction of the stator fault features using the spectral analysis of stator current symmetrical components is presented. In Section 4, the test stand and methodology of the experimental research are presented. Next, in Section 5, the training process of the proposed fault classifier is discussed. In Section 6, the experimental verification of its effectiveness during off-line and on-line tests is presented. Final conclusions from the conducted research are discussed in Section 7.

\section{K-Nearest Neighbors}

The KNN algorithm is one of the most fundamental, simple and effective machine learning algorithms used for data classification [54,55]. To classify unknown data represented by the feature vector as a point in the feature space, the KNN calculates the distance between the new point and points that were used in the training process - the training data set. Then, this classifier assigns the point to the class among its K-nearest neighbors, where $K$ is a pre-determined integer value [56,57].

This concept is shown in Figure 2. The new data point is represented as * If $K$ is equal to 3 , then there are two neighbors in Class A and one in Class B, hence this new data point must belong to Class A. However, if $K=5$, two points in the neighborhood are in Class $\mathrm{A}$, and three are in Class B, so the new data point will be classified as Class B. It follows that the choice of the value of $K$ has a big impact on the accuracy of the trained model [58]. There is no specific way to determine the best $K$ value, so it is necessary to try different values to find the best one.

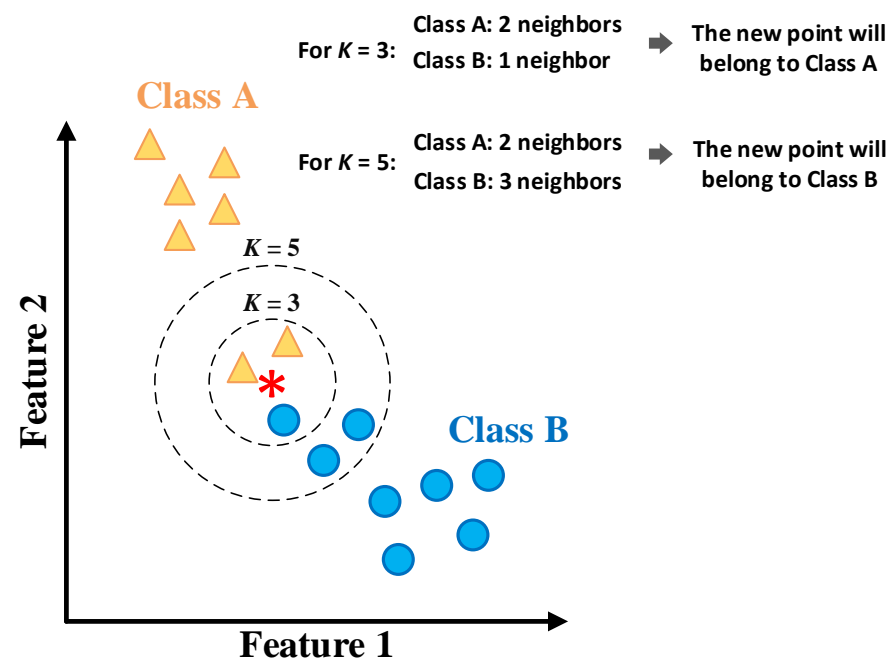

Figure 2. K-Nearest Neighbors classification principle.

Various distance metrics for calculating the distance between adjacent points are presented in the literature [56]. In this work, apart from the impact of the number of $K$ closest neighbors on the accuracy of the classifier, the impact of different distance metrics is also verified.

Let $A$ and $B$ be feature vectors: $A=\left(x_{1}, x_{2}, \ldots, x_{n}\right)$ and $B=\left(y_{1}, y_{2}, \ldots, y_{n}\right)$, where $n$ is the dimensionality of the feature space [48]. The most common functions used to calculate the distance are Euclidean, Minkowski, Mahalanobis and Correlation. These distance metrics are expressed by Equations (1)-(4), respectively. The most popular distance metric 
is the Minkowski distance [59]. Algorithm 1 presented below defines the basic KNN classifier algorithm steps in detail [60].

$$
\begin{gathered}
d_{\text {Euclidean }}(A, B)=\sqrt{\sum_{i=1}^{n}\left(x_{i}-y_{i}\right)^{2}}, \\
d_{\text {Minkowski }}(A, B)=\left(\sum_{i=1}^{n}\left|x_{i}-y_{i}\right|^{r}\right)^{\frac{1}{r}}, \\
d_{\text {Mahalanobis }}(A, B)=\sqrt{\sum_{i=1}^{n}\left(\frac{x_{i}-y_{i}}{\sigma_{i}}\right)^{2}}, \\
d_{\text {Correlation }}(A, B)=\frac{\sum_{i=1}^{n}\left(x_{i}-\bar{x}\right)\left(y_{i}-\bar{y}\right)}{\sqrt{\sum_{i=1}^{n}\left(x_{i}-\bar{x}\right)^{2} \sum_{i=1}^{n}\left(y_{i}-\bar{y}\right)^{2}}},
\end{gathered}
$$

where:

$x_{i}, y_{i}$-elements of the $A$ and $B$ feature vector, respectively;

$n$-feature space dimension;

$r$-order of the Minkowski distance metric;

$\sigma$-standard deviation of the $x_{i}$ and $y_{i}$ over the data set;

$\bar{x}, \bar{y}$-mean value of the $x_{i}$ and $y_{i}$ elements (for $i=1$ to $i=n$ ) of the $A$ and $B$ feature vectors, respectively.

Algorithm 1 The basic KNN algorithm

Data: $D=\left\{A_{i}, c_{i}\right)$, for $i=1$ to $n$, where $A_{i}=\left(x_{1}, x_{2} \ldots, x_{m}\right)$ is an observation that belongs to class $c_{i}, n$ is a number of elements in the data set and $m$ is a number of features in the input vector

Data: $Z=\left(z_{1}, z_{2} \ldots, z_{m}\right)$ new data to be classified

Result: class to which new input data $Z$ belongs

Initialize distances $\leftarrow\{0\}$;

for $A_{i}$ in $D$ do

$d_{i} \leftarrow d\left(A_{i}, Z\right)$;

distances $[i] \leftarrow d_{\mathrm{i}}$;

end

Sort distances $\left\{d_{\mathrm{i}}\right.$, for $i=1$ to $\left.n\right\}$ in ascending order;

Get the first $K$ cases closer to $Z$ (with the shortest distance), $D_{z}^{K}$;

class $\leftarrow$ most frequent class in $D_{z}^{K}$

The most important advantages of the KNN algorithm are:

- $\quad \mathrm{KNN}$ is a simple and easy algorithm to comprehend;

- The hardware implementation of the $\mathrm{KNN}$ algorithm is not complicated;

- The KNN classifier training process is very fast;

- The effectiveness of the KNN algorithm depends only on two key parameters: $K$ value and distance metric;

- The KNN algorithm may constantly evolve if new training data are collected;

- In KNN, there are no assumptions about the input data to be met to implement this algorithm.

However, despite its many advantages, this algorithm has some disadvantages:

- The KNN algorithm is generally not recommended for analyzing very large data sets; 
- To obtain the proper and effective operation of this algorithm, it is necessary to choose the optimal number of $K$, which involves the need to test the algorithm several times during the training process;

- It can be challenging to apply the KNN algorithm to high-dimensional data (a high number of features).

\section{Spectral Analysis of Symmetrical Components of Stator Phase Currents}

The effectiveness of fault classifiers strongly depends on the selected fault features. Therefore, it is essential to select those that are most susceptible to damages. Symptoms of the inter-turn short circuits that allow for their detection at an early stage are still being searched. In this paper, the spectral analysis of the positive and negative sequence symmetrical components of stator phase currents is proposed to extract inter-turn shortcircuit symptoms.

A negative sequence component value of the phase current is a significant indicator of unbalance in motor phases. This unbalance may be caused by short circuits in the stator winding [7]. Zero, positive and negative sequence components of the phase current can be calculated as follows:

$$
\left[\begin{array}{l}
I_{0} \\
I_{1} \\
I_{2}
\end{array}\right]=\frac{1}{3}\left[\begin{array}{ccc}
1 & 1 & 1 \\
1 & a & a^{2} \\
1 & a^{2} & a
\end{array}\right] \cdot\left[\begin{array}{c}
I_{s A} \\
I_{s B} \\
I_{s C}
\end{array}\right]
$$

where:

$I_{0}, I_{1}, I_{2}$-zero, positive and negative stator phase current component in the steady state, respectively;

$I_{S A}, I_{S B}, I_{S C}$-Phases A, B and C stator current, respectively;

And:

$$
a=e^{j \frac{2 \pi}{3}} .
$$

In the case of three-phase PMSMs, the $I_{0}$ component does not exist; therefore, it is necessary to calculate only the positive and negative symmetrical current components.

The matrix Equation (5) concerns the sinusoidal signals of stator phase currents in the steady state. However, supplying motors from Voltage Source Inverters (VSIs) introduces a number of additional harmonics that cause the distortion of voltages and currents. In such cases, in order to use the classic symmetrical component calculation method, it is necessary to filter out the disturbing harmonics or extract the fundamental components of the supply voltage $\left(f_{s}\right)$. In this paper, the second approach is proposed. This approach is based on the calculation of the instantaneous values of the stator current symmetrical components using the $90^{\circ}$ shift operator in the time domain, according to [61]:

$$
\left[\begin{array}{l}
i_{1} \\
i_{2}
\end{array}\right]=\frac{1}{3}\left[\begin{array}{l}
i_{S A}-\frac{1}{2}\left(i_{S B}+i_{S C}\right)+\frac{\sqrt{3}}{2} S_{90}\left(i_{S B}-i_{S C}\right) \\
i_{S A}-\frac{1}{2}\left(i_{S B}+i_{S C}\right)-\frac{\sqrt{3}}{2} S_{90}\left(i_{S B}-i_{S C}\right)
\end{array}\right],
$$

where:

$i_{1}, i_{2}$-instantaneous values of the positive and negative stator phase component, respectively;

$i_{S A}, i_{S B}, i_{S C}$-Phases A, B and C instantaneous values of stator current, respectively;

$S_{90}$ - operator of a phase shift by an angle of $90^{\circ}$ in the time domain.

In the next step, spectral analysis of the instantaneous values of symmetrical current components calculated according to Equation (7) is performed. In Figure 3, the spectra of the stator phase current's positive sequence component (Figure 3a) and negative sequence component (Figure 3b) for PMSM, the parameters of which are grouped in Appendix A, are shown. These spectra concern the operation of the motor at $f_{s}=100 \mathrm{~Hz}\left(n=n_{N}=1500 \mathrm{rpm}\right)$, with nominal load torque $\left(T_{L}=T_{N}\right)$ for an undamaged winding and with a different number of shorted turns $\left(N_{s h}\right)$. 


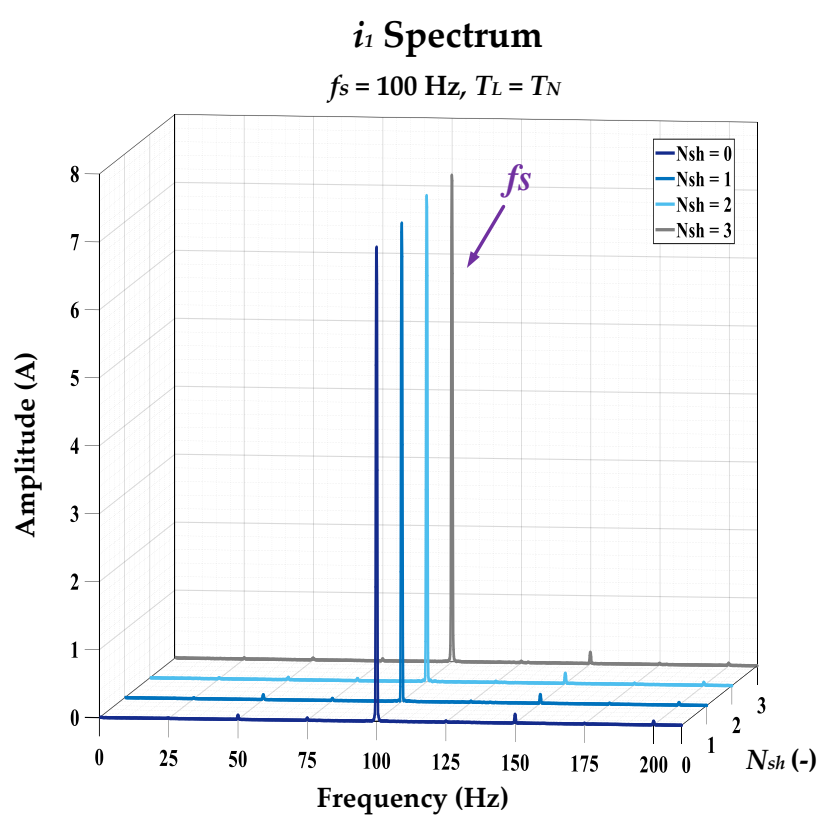

(a)

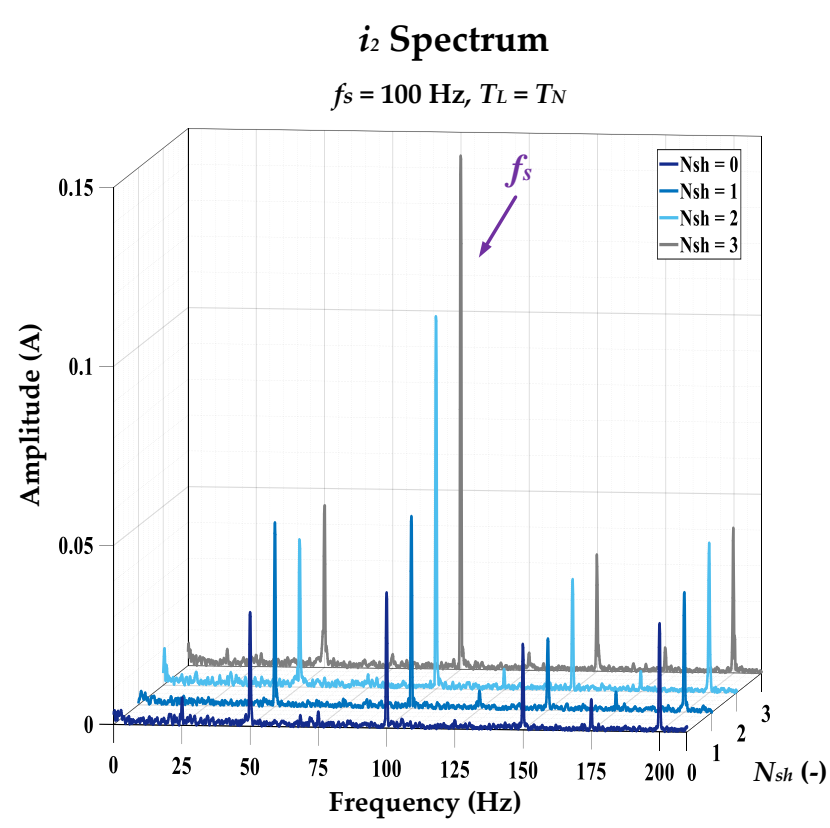

(b)

Figure 3. The impact of shorted turns number in the PMSM stator winding on the FFT spectrum of the positive (a) and negative (b) phase current sequence component: $f_{S}=100 \mathrm{~Hz}, T_{L}=T_{N}$.

In these spectra, an increase in the amplitude of the $f_{s}$ fundamental frequency components after an inter-turn short circuit in the stator winding can be observed. It is clearly visible that the increase in the amplitude of this component due to the inter-turn short circuit is greater for the negative sequence component analysis. In order to clearly define the symbols and avoid misunderstanding, the $f_{s}$ frequency component in the $i_{1}$ spectrum will be hereinafter denoted as $f_{s i 1}$ and in the $i_{2}$ as $f_{s i 2}$.

The effect of the number of shorted turns $N_{s h}$ and the load torque $T_{L}$ on the amplitude value of the $f_{s i_{1}}$ component is shown in Figure $4 \mathrm{a}$, whereas the dependence on the supply voltage frequency value $f_{s}$ is illustrated in Figure $4 \mathrm{~b}$. It can be concluded from the presented results that the load torque changes have an impact on the value of the $f_{s i_{1}}$ component amplitude, but the frequency of supply voltage does not affect these values.

$f_{\text {sit }}$

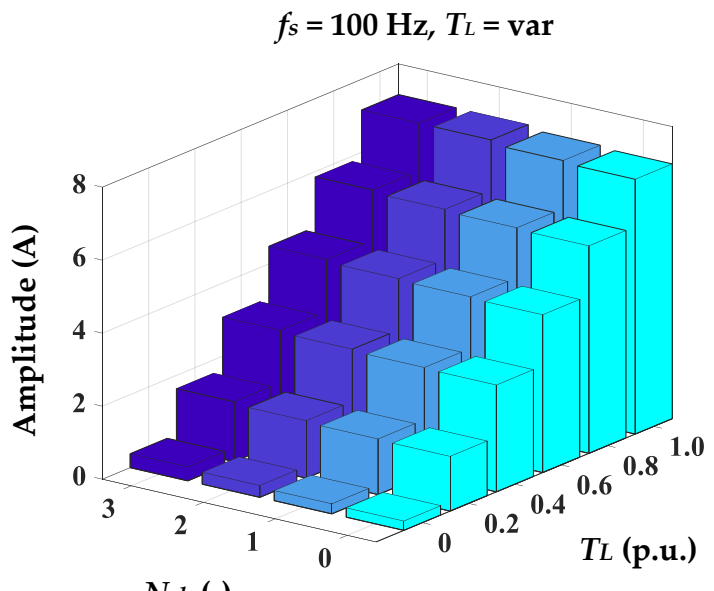

Nsh (-)

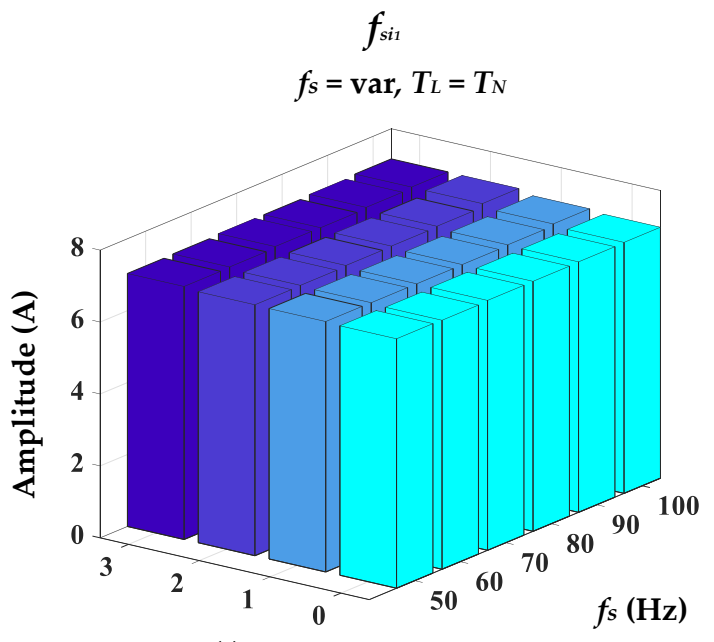

Nsh (-)

(a)

(b)

Figure 4. The impact of shorted turns number in the PMSM stator winding on the level of the amplitude of the $f_{s i 1}$ component in the positive phase current sequence component for variable load torque $T_{L}(\mathbf{a})$ and variable supply frequency $f_{S}(\mathbf{b})$. 
Figure $5 \mathrm{a}, \mathrm{b}$ shows the effect of the number of shorted turns $N_{s h}$, the load torque $T_{L}$ and the power supply frequency voltage $f_{s}$ on the $f_{s i 2}$ component amplitude. The results below show that the $T_{L}$ does not have a significant impact on the value of the $f_{s i 2}$ component amplitude. Moreover, this value increases as a result of inter-turn short circuits in a wide range of the power supply frequency $f_{s}$ (rotational speeds $n$ ). Therefore, it can be concluded that the $f_{s i 2}$ component, because of its changes due to damage to the stator winding, is a very good diagnostic indicator. The greatest sensitivity to the increasing number of shorted turns $N_{\text {sh }}$ occurs when the motor is operating at high rotational speeds, close to the rated value. Based on these observations, it was decided to use the values of the amplitudes of the $f_{s i 1}$ and $f_{s i 2}$ components as input features of the KNN model.

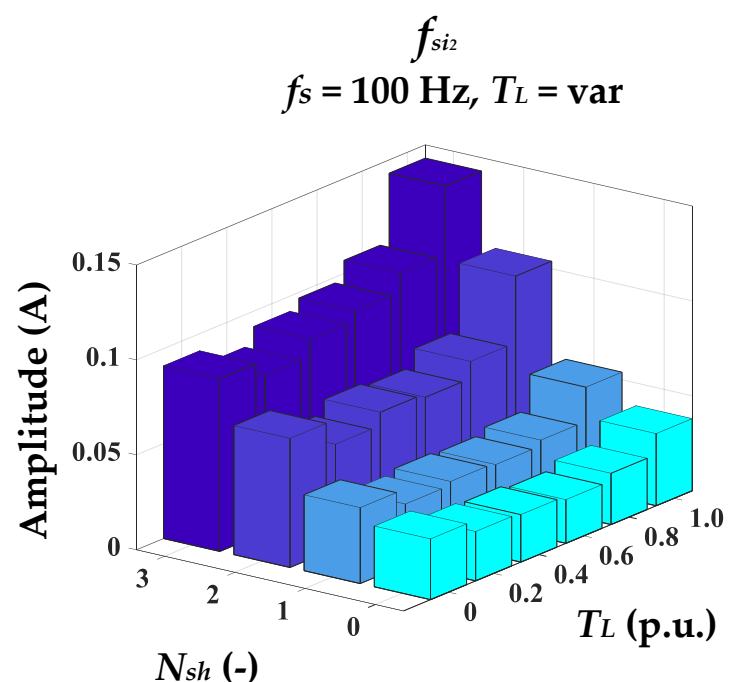

(a)

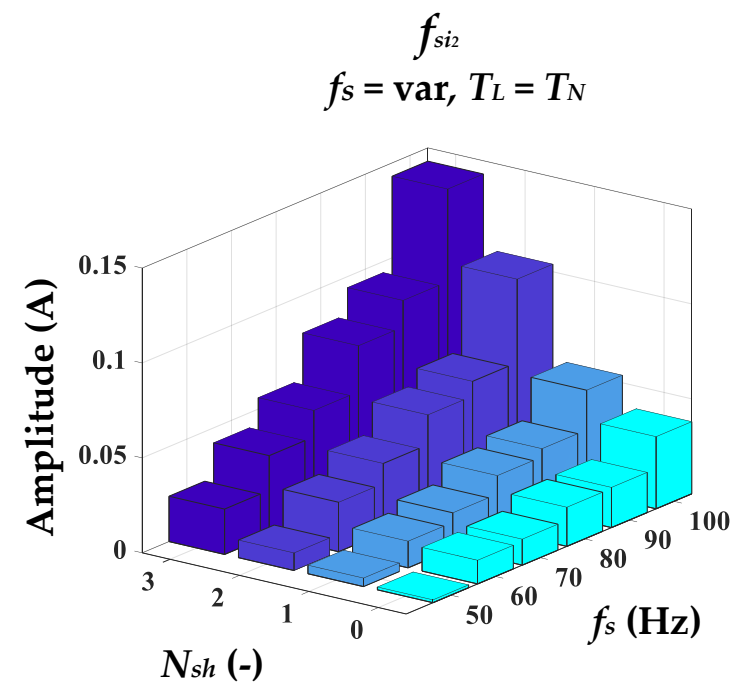

(b)

Figure 5. The impact of shorted turns number in the PMSM stator winding on the level of the amplitude of the $f_{s i 2}$ component in the negative phase current sequence component for variable load torque $T_{L}(\mathbf{a})$ and variable supply frequency $f_{s}(\mathbf{b})$.

It has to be noted that despite the insensitivity of the amplitude $f_{s i 2}$ to the change in $T_{L}$ value, its increase as a result of an inter-turn short-circuit drops with the decreasing frequency of the supply voltage, which is a minor limitation. However, even at a lower speed (power supply frequency), changes due to the stator winding damage are still visible.

\section{Experimental Setup}

The experimental verification of the proposed KNN-based stator winding fault classifier was carried out on a specially designed laboratory setup with PMSM with nominal power equal to $2.5 \mathrm{~kW}$, operating in a closed-loop structure and powered by a VSI. The loading machine was a second PMSM with nominal power equal to $4.7 \mathrm{~kW}$. The laboratory stand is shown in Figure 6. The main parameters of the tested PMSM are grouped in Appendix A.

The construction of the tested PMSM was specially prepared to allow the physical modeling of the inter-turn short circuits of a selected number of turns in a phase. Each of the three phases of the stator winding consists of two coils, 125 turns each. An illustrative schema of the tested PMSM stator winding is shown in Figure 7a. One of the two winding coils in each of the three phases was modified to provide controlled short circuits. This modification consisted of leading out a group of coils to the terminal board. The diagram of the terminal board with the derived phases of the PMSM stator winding is shown in Figure $7 \mathrm{~b}$. During the experimental verification, a maximum of three turns in Phase A was short circuited, which accounted for $1.2 \%$ of all turns in one phase. Direct short circuits were performed by connecting the taps on the terminal board with a wire without limiting the current in a short-circuit loop with an additional resistor. 


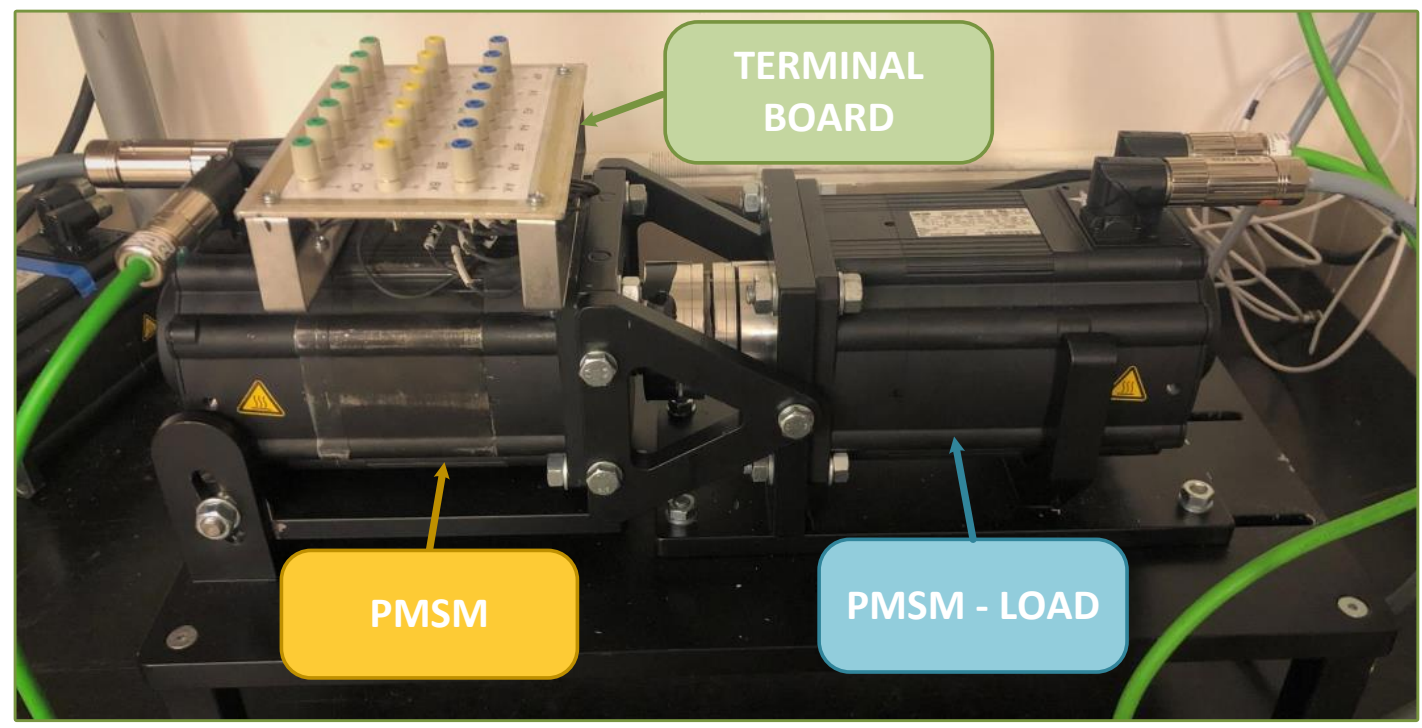

Figure 6. Specially designed laboratory stand.

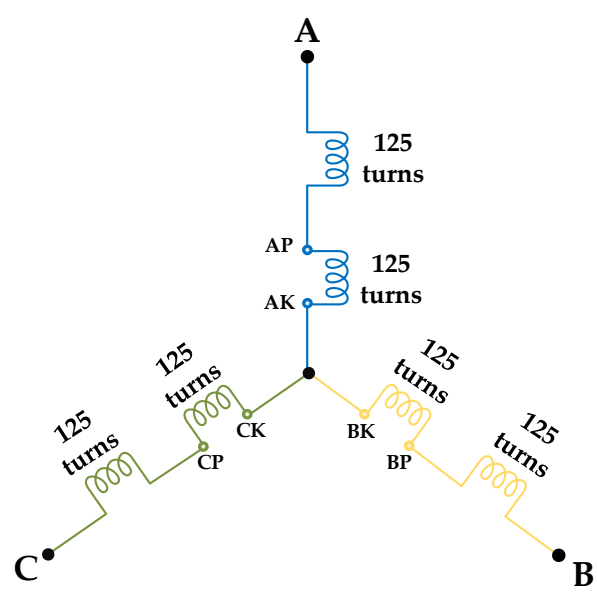

(a)

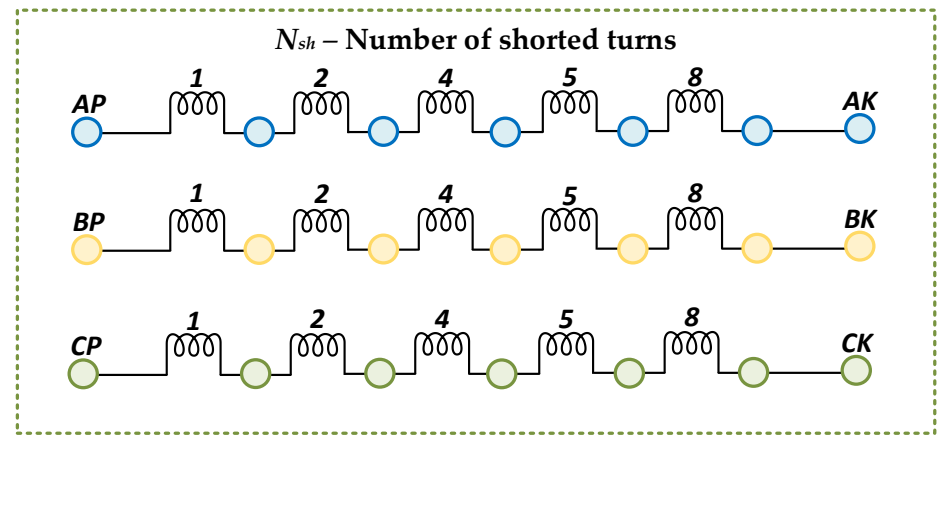

(b)

Figure 7. Illustrative schema of the tested PMSM stator winding $(\mathbf{a}, \mathbf{b})$ diagram of the derived phase terminals of the PMSM stator winding.

The block diagram of the experimental setup is shown in Figure 8. The tested PMSM was fed from an industrial VSI by Lenze. The used diagnostic signals, stator phase currents, were measured with LEM LA 25-NP transducers. The output signals from the transducers were passed to the data acquisition measurement card (DAQ NI PXI-4492) by National Instruments (NI, Austin, TX, USA) and then pre-processed by the LabVIEW programming environment. The sampling frequency of the phase current measurement was equal to $8192 \mathrm{~Hz}$. The DAQ card was placed in the NI PXI 1082 industrial computer. The control of the tested motor was performed in Lenze Engineer software, whereas the load torque was set in Veristand.

The described experimental setup was used to collect the measurement data, which were used for training the proposed KNN classifier and its off-line verification but also for further on-line tests. The experimental studies were carried out for various load torque values in the range of $(0 \div 1) T_{N}$ with $0.2 T_{N}$ step and for various rotational speeds (frequency of the supply voltage $(60 \div 100) \mathrm{Hz}$ ). It allowed evaluating the influence of the motor operating conditions on the effectiveness of the fault classifier. 


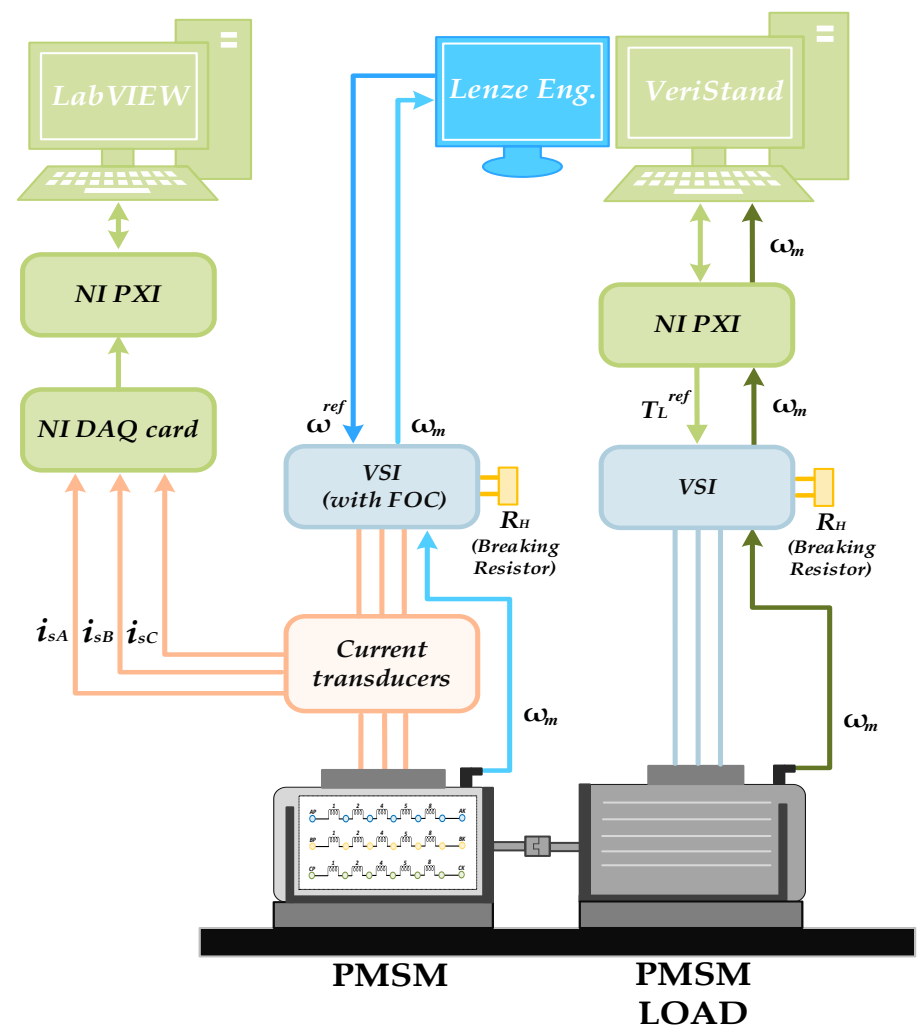

Figure 8. Block diagram of the experimental setup.

\section{Training Process of the Proposed KNN Fault Classifier}

The effectiveness of the classifier model depends on the appropriate selection of its input vector elements, so they have to be carefully selected. This article proposes a spectral analysis of the symmetrical component of the stator phase current for inter-turn short-circuit symptoms extraction, which allowed the selection of a two-element input vector consisting of $f_{s i 1}$ and $f_{s i 2}$ component amplitudes, $X_{i}=\left(A f_{s i 1}, A f_{s i 2}\right)$. In ML, the input data set is typically split into training data and test data. In the training process of the proposed KNN fault classifier model, 240 input vectors corresponding to different states of the stator winding state and operating conditions were used. These conditions are grouped in Table 1.

Table 1. Training data set.

\begin{tabular}{|c|c|c|c|}
\hline Training Packages & $T_{L}$ & $f_{S}$ & $N_{s h}$ \\
\hline $1 \div 60$ & $\begin{array}{l}10 \text { vector packages for each: } 0,0.2 T_{N} \text {, } \\
\quad 0.4 T_{N}, 0.6 T_{N}, 0.8 T_{N}, T_{N}\end{array}$ & \multirow{4}{*}{$100 \mathrm{~Hz}\left(f_{s N}\right)$} & 0 \\
\hline $61 \div 120$ & $\begin{array}{l}10 \text { vector packages for each: } 0,0.2 T_{N} \text {, } \\
\quad 0.4 T_{N}, 0.6 T_{N}, 0.8 T_{N}, T_{N}\end{array}$ & & 1 \\
\hline $121 \div 180$ & $\begin{array}{l}10 \text { vector packages for each: } 0,0.2 T_{N} \text {, } \\
0.4 T_{N}, 0.6 T_{N}, 0.8 T_{N}, T_{N}\end{array}$ & & 2 \\
\hline $181 \div 240$ & $\begin{array}{l}10 \text { vector packages for each: } 0,0.2 T_{N} \text {, } \\
0.4 T_{N}, 0.6 T_{N}, 0.8 T_{N}, T_{N}\end{array}$ & & 3 \\
\hline
\end{tabular}

The distribution of the training data points is shown in Figure 9. Due to the fact that the classifier input vector is a two-element vector, it can be represented in the Cartesian coordinate system (two-dimensional space). Based on the analysis of the scatter chart (Figure 9), it can be concluded that these input features are promising fault symptoms, as there is a clear distribution of classes. These classes correspond to the stator winding states of the tested PMSM. 


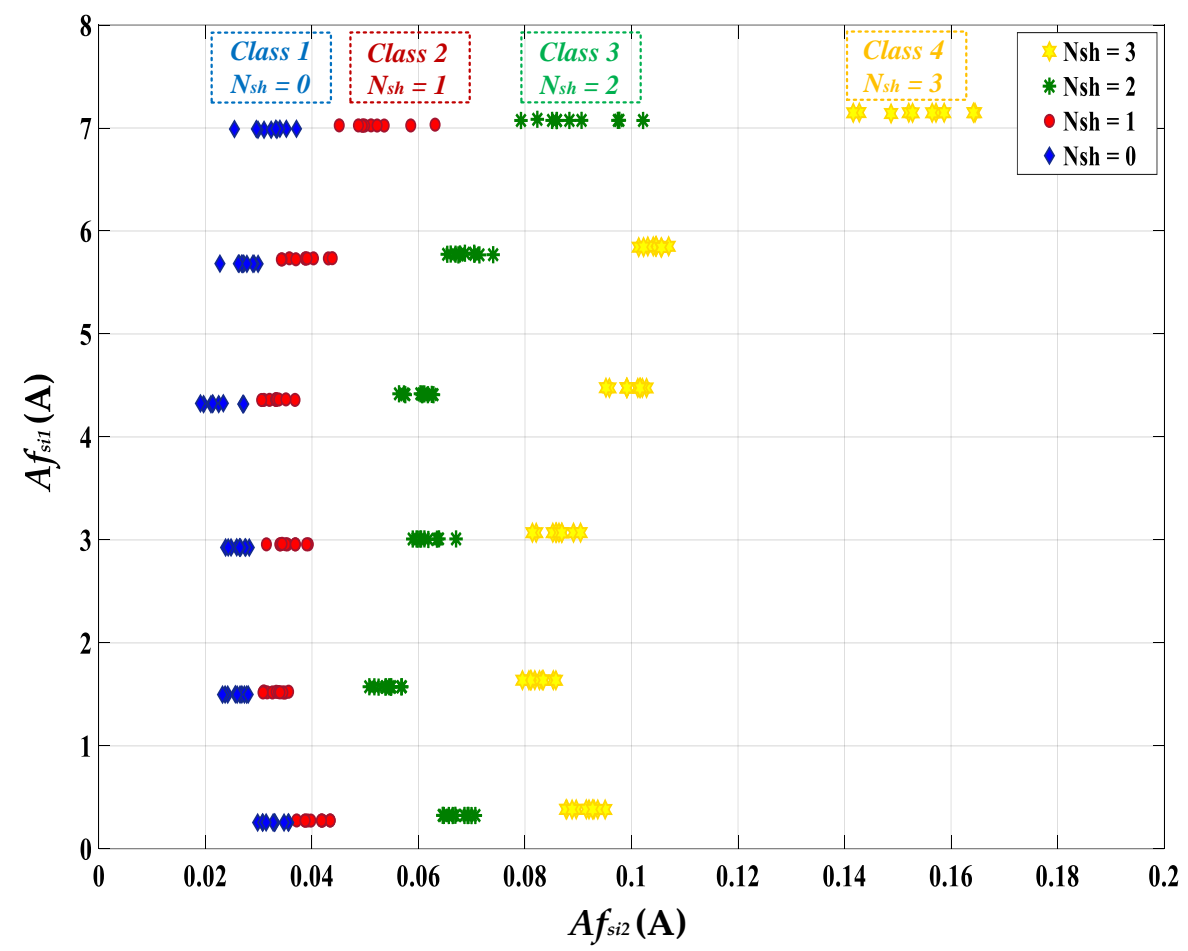

Figure 9. Distribution of the proposed fault features for different $N_{s h}$.

To choose the best model of the KNN, the accuracy of the classifiers was verified for four different distance metrics, which are described by Equations (1)-(4) and a different number of K-nearest neighbors. The impact of these parameters is very often overlooked in papers on the application of KNN, especially with regard to the electric motor fault diagnosis. The classifier's model accuracy for different configurations is shown in Figure 10 and grouped in Table 2. Based on these values, it is concluded that $100 \%$ accuracy of the KNN model to the training data set was achieved for KNN with the Euclidean, Minkowski and Mahalanobis distance metrics both for $K=3$ and $K=5$. The verification of the influence of the $K$ value on the accuracy of the model led to the conclusion that a value that is too large may cause a significant decrease in the accuracy of the classifier. An increasing number of nearest neighbors is connected with the phenomenon of overfitting, which is clearly confirmed by the discussed results. Moreover, a large $K$ value significantly increases the computational complexity of the algorithm. A $K$ that is too low will increase bias and cause misclassifications, leading to underfitting [62]. In the analyzed case, the underfitting is visible for $K=1$ and $K=2$. Furthermore, setting $K$ to an odd value helps to eliminate the possibility of a statistical stalemate and invalid results.

Nonetheless, the inverse trend is characteristic for $\mathrm{KNN}$ with the Correlation distance metric. In this case, for low values of the $K$ parameter, the classifier accuracy has the lowest value and gradually increases with increasing $K$. This is typical for a function that takes into account the correlation between two points.

To choose the best configuration from those characterized by $100 \%$ accuracy, the times needed to train each type are compared in Figure 11. The fastest training time was obtained for $\mathrm{KNN}$ with the Euclidean distance metric and $K=3$. Based on this detailed analysis, the authors decided to carry out the off-line and on-line experimental verification tests for this classifier. 


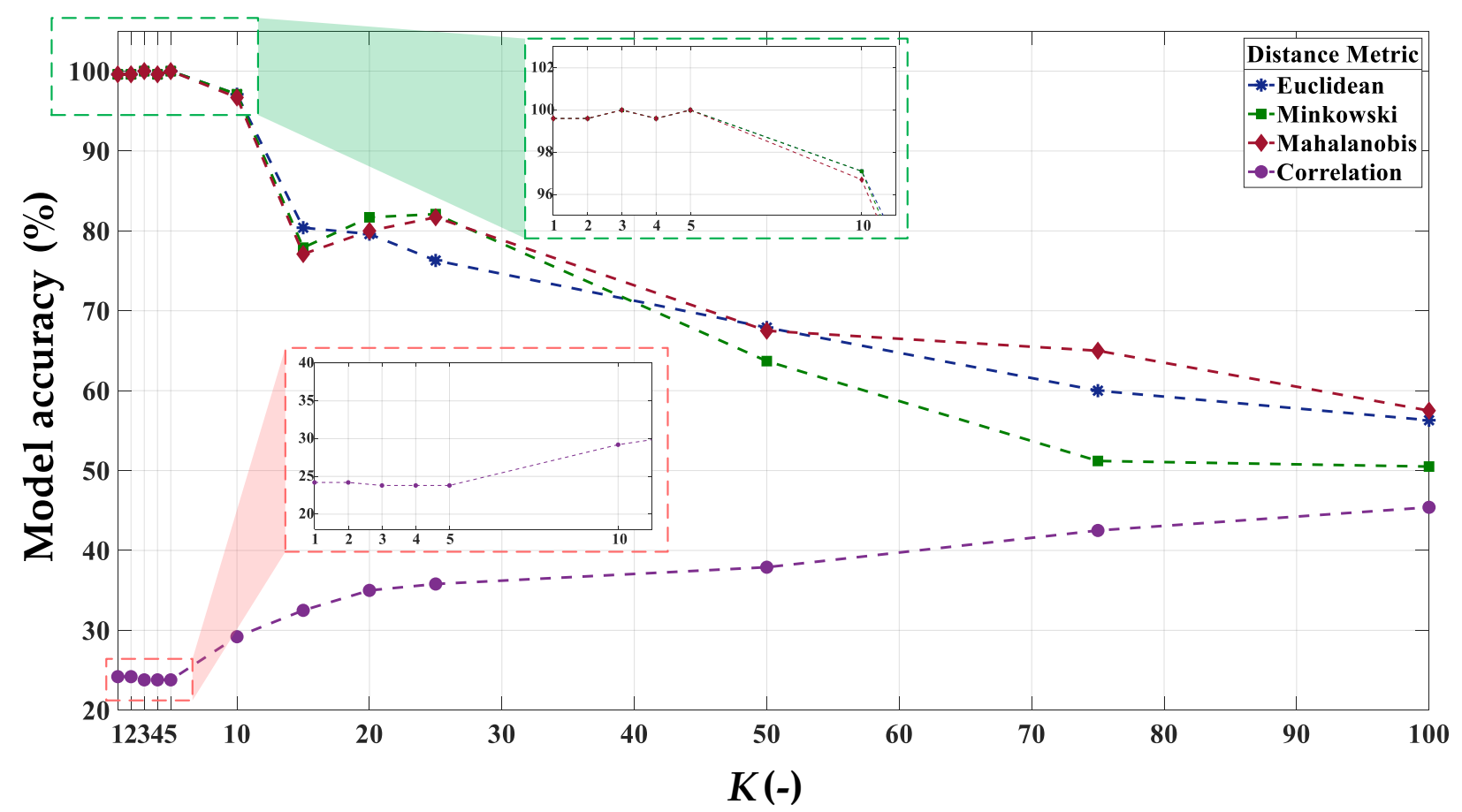

Figure 10. The impact of the K-nearest neighbors value and distance metric on the KNN classifier accuracy.

Table 2. The KNN classifier accuracy for selected key parameters.

\begin{tabular}{ccccc}
\hline \multirow{2}{*}{$\mathbf{N}^{-}$} & \multicolumn{4}{c}{ Distance Metric } \\
\cline { 2 - 5 } & Euclidean & Minkowski & Mahalanobis & Correlation \\
\hline 1 & $99.6 \%$ & $99.6 \%$ & $99.6 \%$ & $24.2 \%$ \\
\hline 2 & $99.6 \%$ & $99.6 \%$ & $99.6 \%$ & $24.2 \%$ \\
\hline 3 & $\mathbf{1 0 0 . 0} \%$ & $\mathbf{1 0 0 . 0} \%$ & $\mathbf{1 0 0 . 0} \%$ & $23.8 \%$ \\
\hline 4 & $99.6 \%$ & $99.6 \%$ & $99.6 \%$ & $23.8 \%$ \\
\hline 5 & $\mathbf{1 0 0 . 0} \%$ & $\mathbf{1 0 0 . 0} \%$ & $\mathbf{1 0 0 . 0} \%$ & $23.8 \%$ \\
\hline 10 & $97.1 \%$ & $97.1 \%$ & $96.7 \%$ & $29.2 \%$ \\
\hline 15 & $80.4 \%$ & $77.9 \%$ & $77.1 \%$ & $32.5 \%$ \\
\hline 20 & $79.6 \%$ & $81.7 \%$ & $80.0 \%$ & $35.0 \%$ \\
\hline 25 & $76.3 \%$ & $82.1 \%$ & $81.7 \%$ & $35.8 \%$ \\
\hline 50 & $67.9 \%$ & $63.7 \%$ & $67.5 \%$ & $37.9 \%$ \\
\hline 75 & $60.0 \%$ & $51.2 \%$ & $65.0 \%$ & $42.5 \%$ \\
\hline 100 & $56.3 \%$ & $50.5 \%$ & $57.5 \%$ & $45.4 \%$ \\
\hline
\end{tabular}




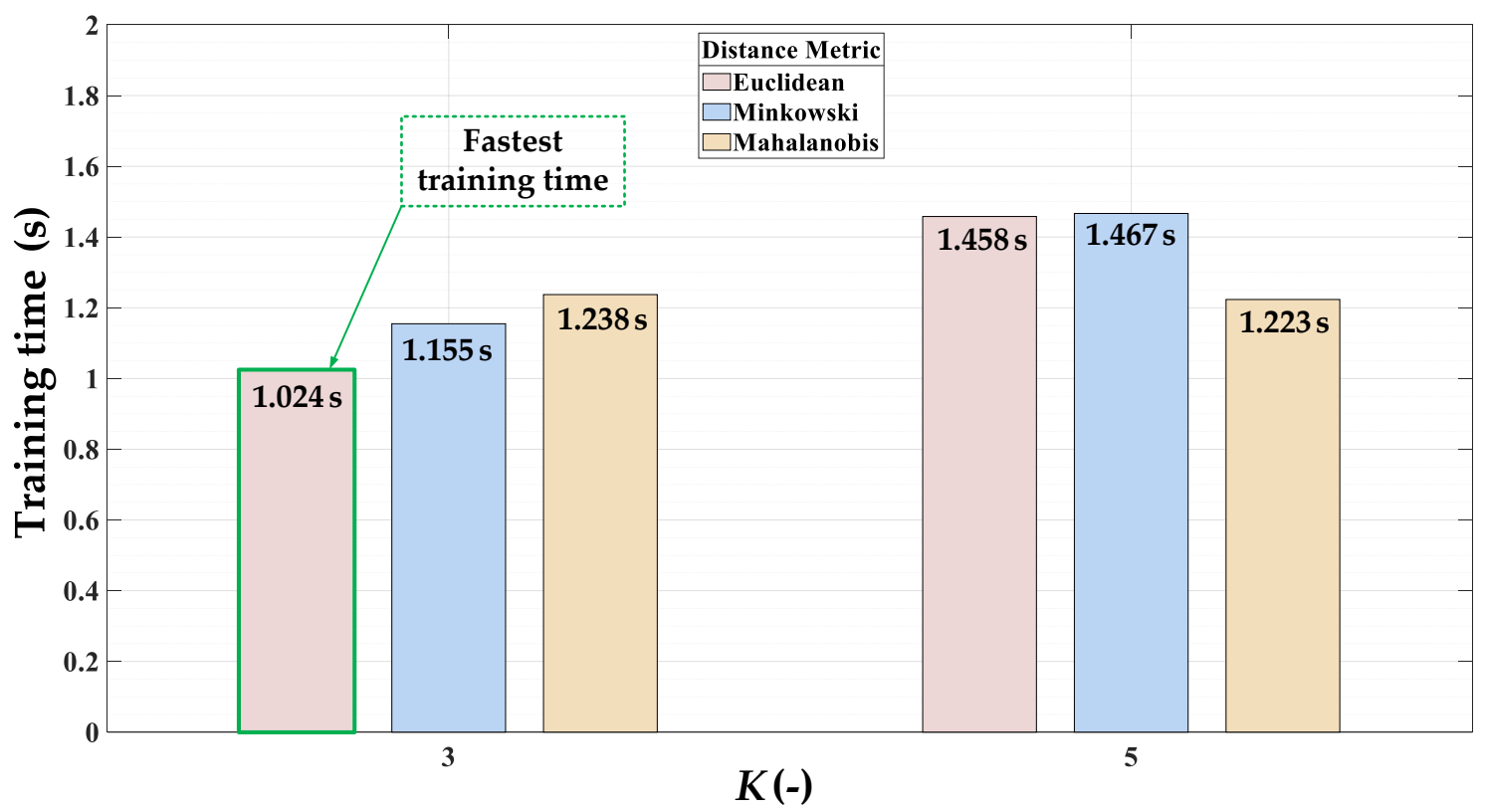

Figure 11. The impact of the K-nearest neighbors value and distance metric on the KNN classifier training time.

\section{The Off-Line and On-Line Verification of the KNN-Based Fault Classifier}

In the process of verification of the classifier's operation during the off-line tests, a set of test data was used. This set consisted of 120 input vectors that were not involved in the KNN training process and corresponded to different states of the stator winding state $\left(N_{\text {sh }}\right)$ and operating conditions $\left(T_{L}\right)$. These conditions are grouped in Table 3 .

Table 3. Test data set.

\begin{tabular}{|c|c|c|c|}
\hline Training Packages & $T_{L}$ & $f_{S}$ & $N_{s h}$ \\
\hline $1 \div 30$ & $\begin{array}{l}5 \text { vector packages for each: } 0,0.2 T_{N} \\
0.4 T_{N}, 0.6 T_{N}, 0.8 T_{N}, T_{N}\end{array}$ & \multirow{4}{*}{$100 \mathrm{~Hz}\left(f_{s N}\right)$} & 0 \\
\hline $31 \div 60$ & $\begin{array}{l}5 \text { vector packages for each: } 0,0.2 T_{N} \text {, } \\
\quad 0.4 T_{N}, 0.6 T_{N}, 0.8 T_{N}, T_{N}\end{array}$ & & 1 \\
\hline $61 \div 90$ & $\begin{array}{l}5 \text { vector packages for each: } 0,0.2 T_{N} \\
\quad 0.4 T_{N}, 0.6 T_{N}, 0.8 T_{N}, T_{N}\end{array}$ & & 2 \\
\hline $91 \div 120$ & $\begin{array}{l}5 \text { vector packages for each: } 0,0.2 T_{N} \\
0.4 T_{N}, 0.6 T_{N}, 0.8 T_{N}, T_{N}\end{array}$ & & 3 \\
\hline
\end{tabular}

In order to assess the effectiveness of the proposed stator winding fault classifier, the $C_{E F F}$ index was introduced, which determines the ratio of the correctly classified stator winding states to the number of input vectors-the sum of the correct classifications and misclassifications. This index is defined by the following equation:

$$
C_{E F F}=\frac{Y_{C}}{Y_{C}+Y_{M}} \cdot 100 \%
$$

where:

$Y_{C}-$ number of correct stator winding state classifications performed by the proposed KNN model;

$Y_{M}$-number of stator winding state misclassifications performed by the proposed KNN model.

The KNN classifier's response to the test data set is shown in Figure 12. The $C_{E F F}$ value of this classifier for the vectors that were not used in the learning process is equal to $100 \%$. It means that the classifier's response was correct for each of the investigated PMSM 
stator winding states and also for only one shorted turn in a coil at a very early stage of the failure.

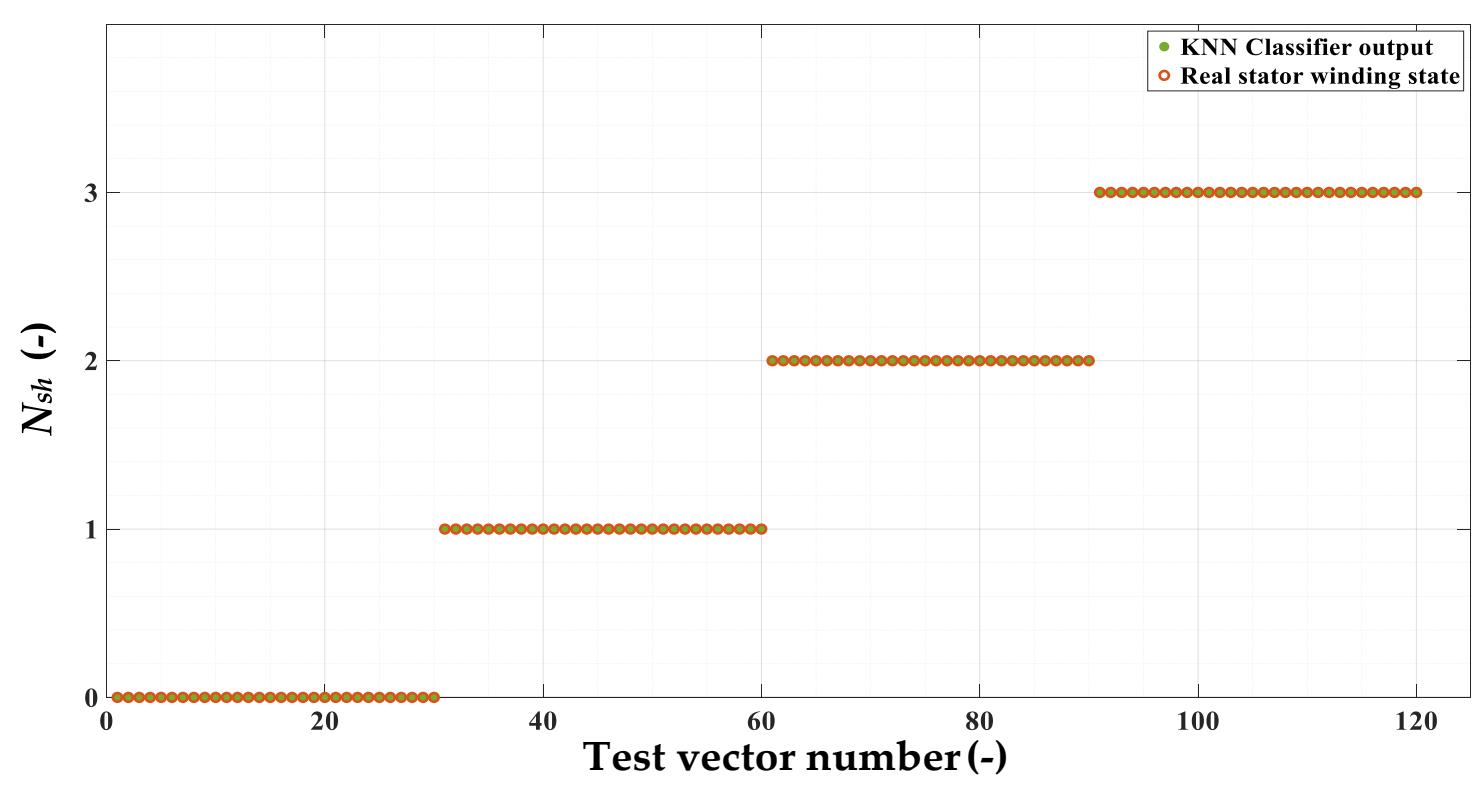

Figure 12. KNN stator winding fault classifier response to the test data set.

Off-line verification tests showed that this classifier provides high efficiency in the detection and classification of inter-turn short circuits. For this reason, it was decided to continue experimental tests during the on-line operation of the drive system.

The flowchart of the proposed on-line fault classification algorithm is shown in Figure 13. The diagnostic application responsible for the data acquisition and signal pre-processing (calculation and spectral analysis of $i_{1}$ and $i_{2}$ ) was developed in the LabVIEW programming environment. The script to call pre-trained KNN stator winding state classifier model was prepared in MATLAB.

\section{DabVIEW}

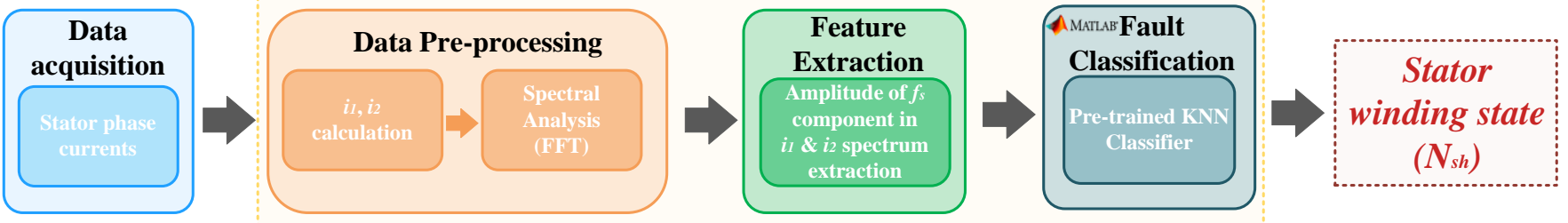

Figure 13. Flowchart of the proposed on-line fault classification algorithm.

The first on-line verification scenario (Test 1 ) was carried out for motor operation in such conditions for which the model of the KNN classifier was trained, i.e., $T_{L}=(0 \div 1) T_{N}$ with a $0.2 T_{N}$ step and $f_{s}=f_{s N}=100 \mathrm{~Hz}$. In this scenario, one, two and three turns were short circuited for several seconds. This is referred to hereinafter as steady short circuits. The efficiency of the classifier $C_{E F F}$ for this condition was as high as $99.4 \%$. The classifier responses and the actual states of the stator winding during this scenario are shown in Figure 14. 


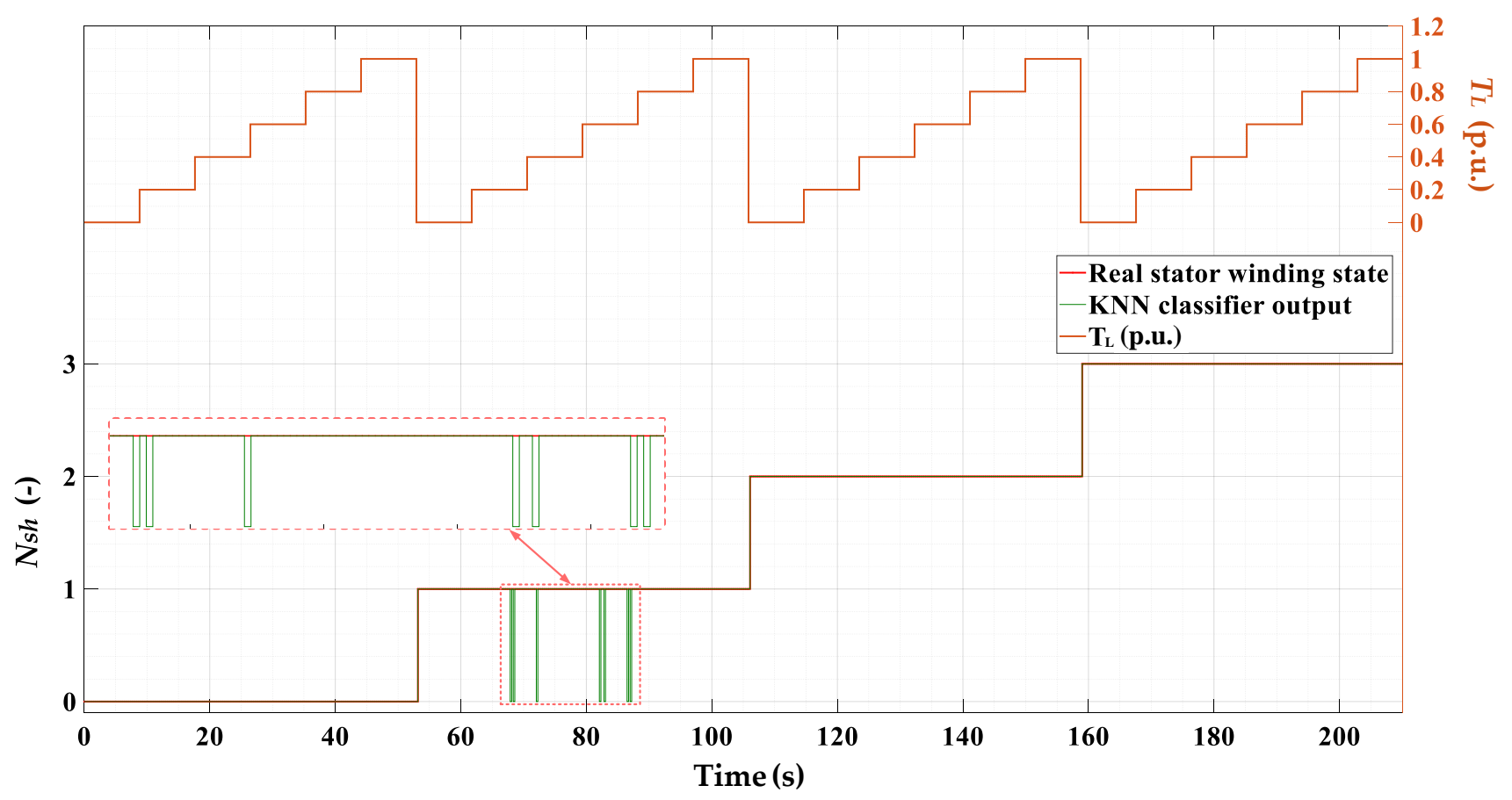

Figure 14. KNN-based stator winding fault classifier responses during the on-line operation-Test $1\left(f_{s}=100 \mathrm{~Hz}, T_{L}=\right.$ var).

In the next scenario (Test 2), the operation of the proposed KNN classifier was verified during the momentary (for $1 \div 2 \mathrm{~s}$ ) short circuiting of one, two and three shorted turns, respectively. This test was also carried out for different load torques $T_{L}=(0 \div 1) T_{N}$ and $f_{s}=f_{S N}=100 \mathrm{~Hz}$. In this case, the $C_{E F F}$ was equal to $98.6 \%$, which confirmed the satisfying properties of this solution (Figure 15).

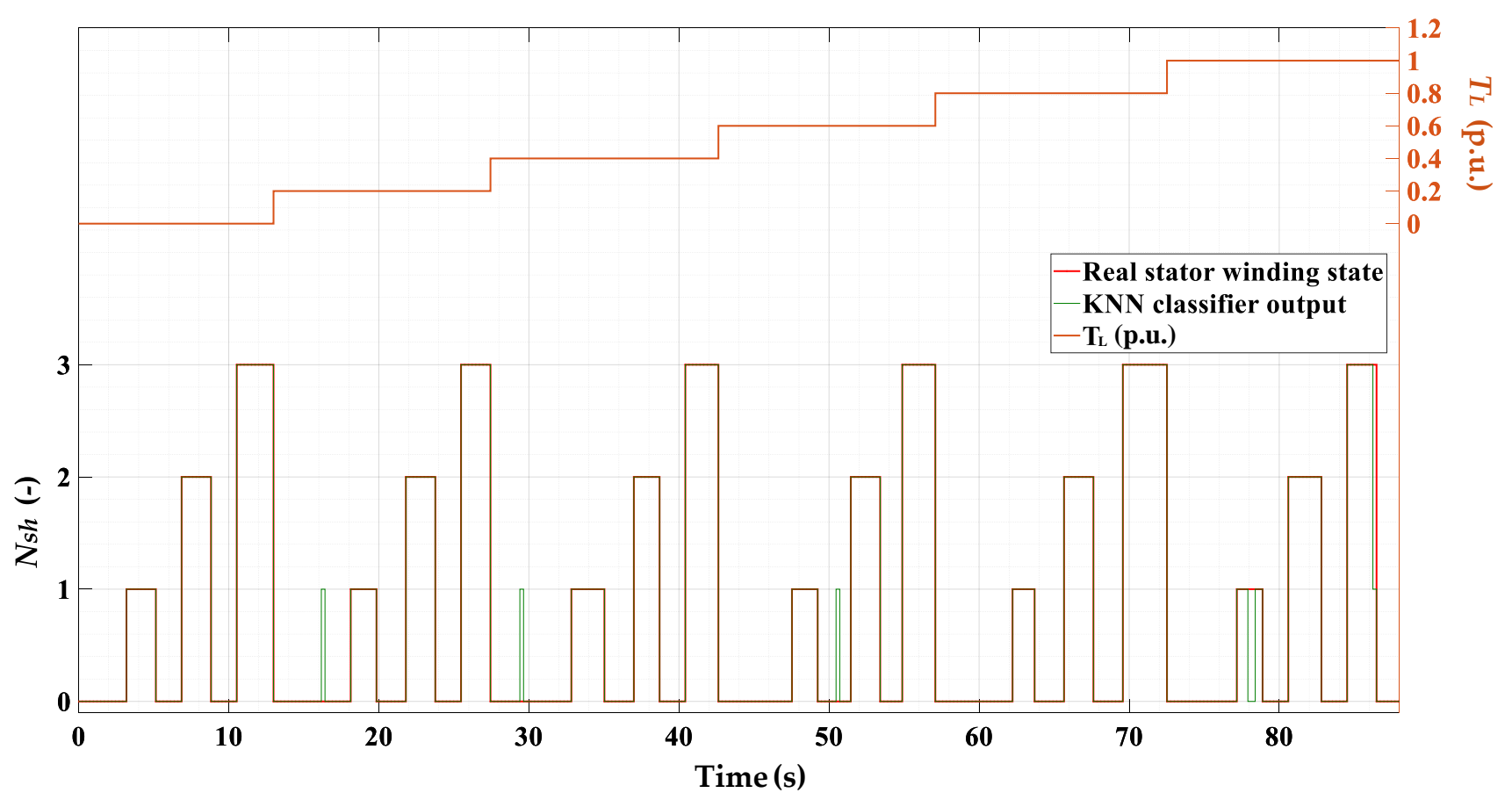

Figure 15. KNN-based stator winding fault classifier responses during the on-line operation-Test $2\left(f_{s}=100 \mathrm{~Hz}, T_{L}=\right.$ var).

Finally, the last test (Test 3) was carried out to verify the classifier operation for power supply frequency (rotational speeds) different from the rated value $\left(f_{S N}\right)$. Before the test, the training data set was extended with vectors corresponding to the motor operation at 
frequencies lower than the rated one $-f_{s}=\{90 \mathrm{~Hz} ; 80 \mathrm{~Hz} ; 70 \mathrm{~Hz} ; 60 \mathrm{~Hz}\}$. With this set, the classifier was re-trained without changing its parameters, and an on-line verification test was performed. The classifier responses and the actual states of the stator winding for such motor operating conditions are shown in Figure 16. As can be seen, the supply voltage frequency was reduced with a step of $10 \mathrm{~Hz}$ down to the value of $60 \mathrm{~Hz}$. In this test, the KNN correctly recognizes the stator winding state in $99.5 \%$ of all cases.

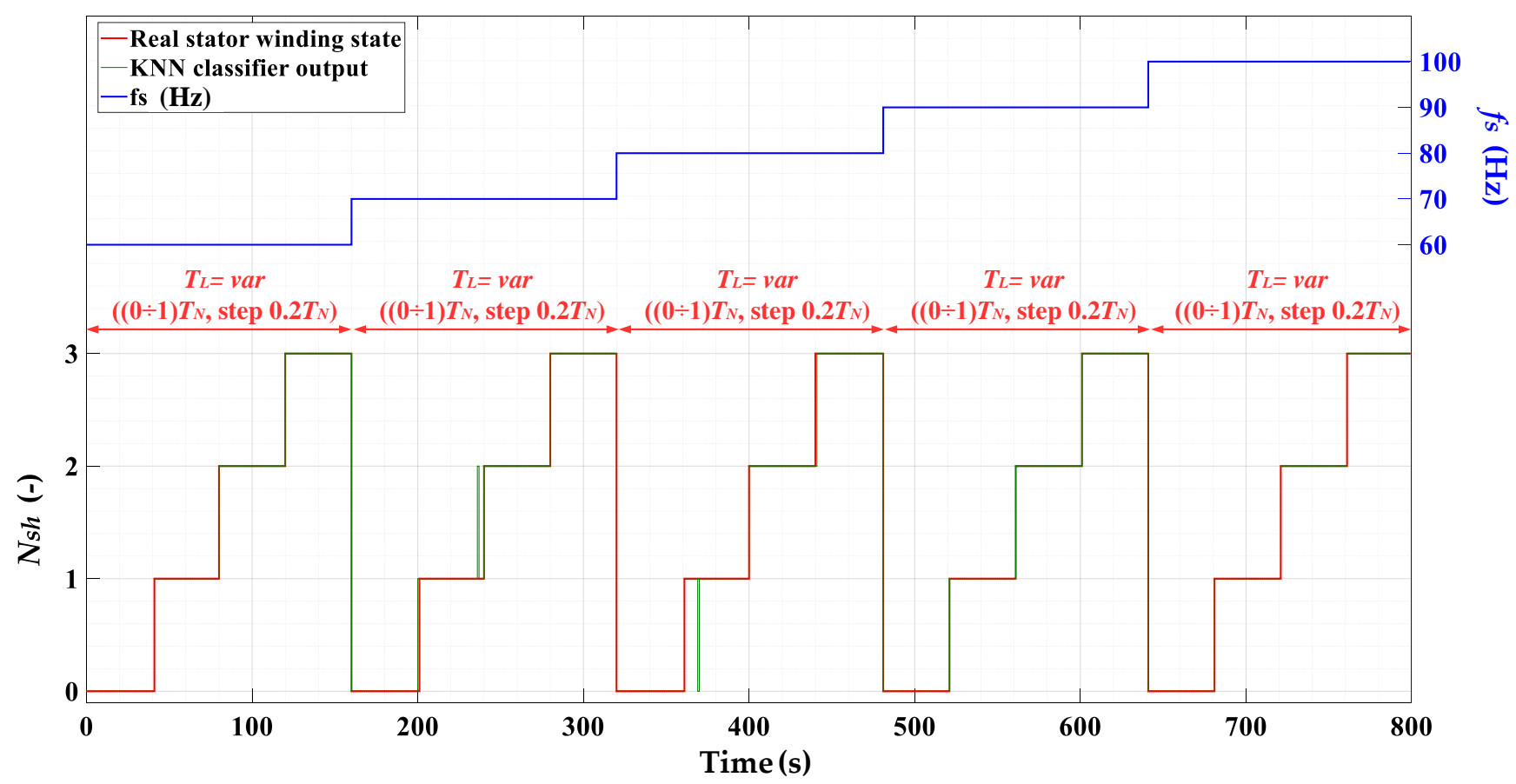

Figure 16. KNN-based stator winding fault classifier responses during the on-line operation-Test $3\left(f_{s}=\operatorname{var}, T_{L}=\operatorname{var}\right)$.

The confusion matrices for each of the test scenarios are shown in Figure 17. The analysis of these matrices shows that the most misclassifications (7.4\%) were found in the case of distinguishing between an undamaged PMSM stator winding and one shorted turn in the coil during Test 2. Nonetheless, it should be emphasized that in each of the discussed cases the effectiveness of winding states classifications is very high, especially that it has been tested on a real drive system during the on-line operation, where disturbances and motor parameters change such as temperature also have a negative influence.

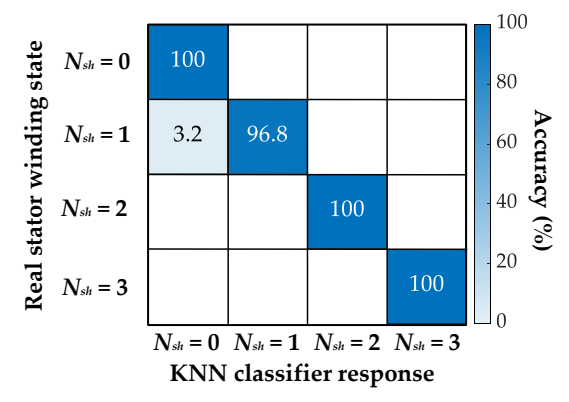

(a)

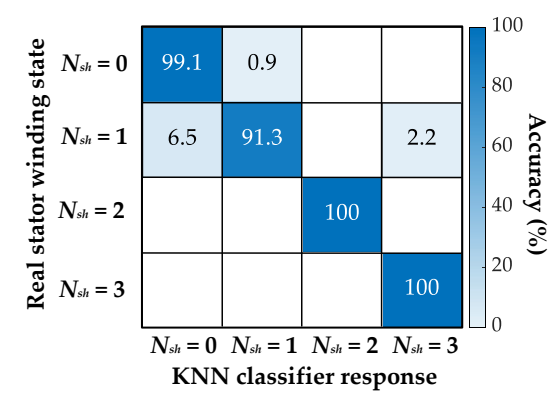

(b)

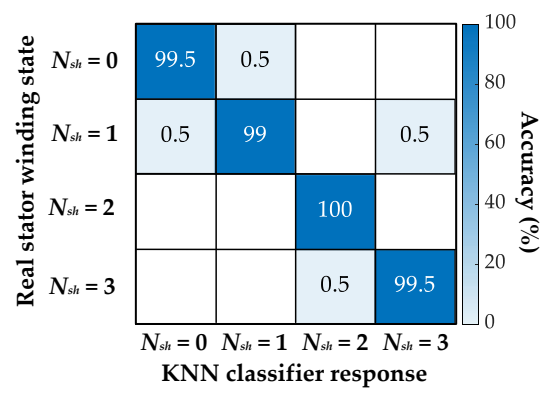

(c)

Figure 17. Confusion matrices for the on-line operation of the fault classifier: Test 1 (a), Test 2 (b) and Test 3 (c).

Moreover, in order to summarize the on-line tests and clarify the scenarios, they are described in Table 4, while classifier key parameters, properties and $C_{E F F}$ values are grouped in Table 5. The analysis of Table 5 allows concluding that the proposed construction of the classifier input vector and its parameters allow achieving very good 
efficiency in the detection of inter-turn short circuits with a resolution to one turn at an early stage of the damage.

Table 4. Details of the test scenarios.

\begin{tabular}{|c|c|c|c|c|}
\hline Test Scenario & Description & $f_{S}$ & $N_{s h}$ & $T_{L}$ \\
\hline 1 & $\begin{array}{l}\text { One, two and three turns were short circuited for several } \\
\text { seconds (steady short-circuits). The motor was operating } \\
\text { under the following conditions: } T_{L}=(0 \div 1) T_{N} \text { with a } \\
\quad 0.2 T_{N} \text { step and nominal supply frequency. }\end{array}$ & $100 \mathrm{~Hz}\left(f_{s N}\right)$ & $0 ; 1 ; 2 ; 3$ & var \\
\hline 2 & $\begin{array}{l}\text { The momentary (for } 1 \div 2 \mathrm{~s} \text { ) short-circuiting of one, two } \\
\text { and three shorted turns was conducted. The motor was } \\
\text { operating under the following conditions: } T_{L}=(0 \div 1) T_{N} \\
\text { with a } 0.2 T_{N} \text { step and nominal supply frequency. }\end{array}$ & $100 \mathrm{~Hz}\left(f_{s N}\right)$ & $0 ; 1 ; 2 ; 3$ & var \\
\hline 3 & $\begin{array}{l}\text { One, two and three turns were short circuited for several } \\
\text { seconds (steady short-circuits). The motor was operating } \\
\text { under the following conditions: } T_{L}=(0 \div 1) T_{N} \text { with a } \\
0.2 T_{N} \text { step and } f_{s}=(60 \div 100) \mathrm{Hz} \text { with } 10 \mathrm{~Hz} \text { step. }\end{array}$ & var & $0 ; 1 ; 2 ; 3$ & var \\
\hline
\end{tabular}

Table 5. Parameters of the proposed KNN classifier model.

\begin{tabular}{cc}
\hline Parameter & Value \\
\hline Accuracy & $100 \%$ \\
\hline Validation (off-line test) & $100 \%$ \\
\hline$C_{E F F}($ On-Line Test 1) & $99.3 \%$ \\
\hline$C_{E F F}($ On-Line Test 2$)$ & $98.6 \%$ \\
\hline$C_{E F F}($ On-Line Test 3) & $99.5 \%$ \\
\hline Average $C_{E F F}$ & $99.1 \%$ \\
\hline Distance metric & Euclidean \\
\hline Distance weight & Equal \\
\hline$K$ & 3 \\
\hline Training time & $1.024 \mathrm{~s}$ \\
\hline
\end{tabular}

The analysis of the results of all three tests showed that in most cases, when there is a misclassification, it occurs for a condition where there is one shorted turn in the PMSM stator winding coil. However, these misclassifications do not occur as often, so it can be considered that they are a significant limitation of the proposed method.

\section{Conclusions}

This paper focuses on the two important elements of electric motors diagnosis-the extraction of failure symptoms and fault classification. For the successful realization of the first issue, the spectral analysis of negative and positive symmetrical components was proposed. For the detection and classification of the inter-turn short circuits of PMSM stator winding, a simple machine learning algorithm (KNN) was successfully implemented. The presented experimental research results confirm the effectiveness of such a solution, even during the on-line operation of the drive system under different motor operating conditions. What has not been analyzed in the diagnostic literature, the verification of the key parameters of the KNN classifier on its effectiveness, was discussed and compared in detail. To evaluate the classifier's effectiveness, the $C_{E F F}$ index was introduced, the average value of which during the on-line tests was equal to $99.1 \%$. Moreover, the proposed classifier allows achieving very good efficiency in inter-turn short-circuit detection with a resolution to one turn at a very early stage of the winding damage. 
The original virtual diagnostic tool developed in the LabVIEW and MATLAB environments performed the function of data acquisition, diagnostic signal pre-processing, extraction of stator winding failure-sensitive symptoms and fault detection and classification. In addition to very good fault classification effectiveness, the training time, which is only $1.024 \mathrm{~s}$, should be highlighted as an important advantage of the proposed solution. Compared to artificial neural networks, especially those with a deep structure, which can take up to several hours to train, this is a clear advantage. Due to the low computational complexity of the KNN classifier, the algorithm that is described in the paper, it will be easy to implement even on a low-cost micro-controller.

Author Contributions: All of the authors contributed equally to the concept of the paper, and proposed the methodology; investigation and formal analyses, P.P. and M.W.; software and data curation, P.P.; measurements, P.P. and M.W.; proposed the paper organization, P.P. and M.W.; validated the obtained results, M.W. All authors have read and agreed to the published version of the manuscript.

Funding: This research was supported by the National Science Center of Poland under grant number 2017/27/B/ST7/00816.

Conflicts of Interest: The authors declare no conflict of interest.

\section{Appendix A}

Table A1. Rated parameters of the tested PMSM.

\begin{tabular}{cccc}
\hline Name of the Parameter & Symbol & Units & \\
\hline Power & $P_{N}$ & 2500 & $\mathrm{~W}$ \\
Torque & $T_{N}$ & 16 & $\mathrm{Nm}$ \\
Speed & $N_{N}$ & 1500 & $\mathrm{r} / \mathrm{min}$ \\
Stator phase voltage & $U_{S N}$ & 325 & $\mathrm{~V}$ \\
Stator current & $I_{S N}$ & 6.6 & $\mathrm{~A}$ \\
Frequency & $f_{s N}$ & 100 & $\mathrm{~Hz}$ \\
Pole pairs number & $p_{p}$ & 4 & - \\
Number of stator phase turns & $N_{S}$ & $2 \times 125$ & - \\
\hline
\end{tabular}

\section{References}

1. Mishra, I.; Tripathi, R.N.; Singh, V.K.; Hanamoto, T. Step-by-Step Development and Implementation of FS-MPC for a FPGA-Based PMSM Drive System. Electronics 2021, 10, 395. [CrossRef]

2. Gherabi, Z.; Toumi, D.; Benouzza, N.; Henini, N. Modeling and Diagnosis of Stator Winding Faults in PMSM Using Motor Current Signature Analysis. In Proceedings of the 2019 International Aegean Conference on Electrical Machines and Power Electronics (ACEMP) 2019 International Conference on Optimization of Electrical and Electronic Equipment (OPTIM), Istanbul, Turkey, 2-4 September 2019; pp. 227-232.

3. Hoai, H.-K.; Chen, S.-C.; Than, H. Realization of the Sensorless Permanent Magnet Synchronous Motor Drive Control System with an Intelligent Controller. Electronics 2020, 9, 365. [CrossRef]

4. Park, G.; Kim, G.; Gu, B.-G. Sensorless PMSM Drive Inductance Estimation Based on a Data-Driven Approach. Electronics 2021, 10, 791. [CrossRef]

5. He, J.; Somogyi, C.; Strandt, A.; Demerdash, N.A.O. Diagnosis of Stator Winding Short-Circuit Faults in an Interior Permanent Magnet Synchronous Machine. In Proceedings of the 2014 IEEE Energy Conversion Congress and Exposition (ECCE), Pittsburgh, PA, USA, 14-18 September 2014; pp. 3125-3130.

6. Huang, S.; Aggarwal, A.; Strangas, E.G.; Li, K.; Niu, F.; Huang, X. Robust Stator Winding Fault Detection in PMSMs With Respect to Current Controller Bandwidth. IEEE Trans. Power Electron. 2021, 36, 5032-5042. [CrossRef]

7. Cira, F.; Arkan, M.; Gümüs, B. A New Approach to Detect Stator Fault in Permanent Magnet Synchronous Motor. In Proceedings of the IEEE International Symposium on Diagnostics for Electric Machines, Power Electronics and Drives (SDEMPED), Guarda, Portugal, 1-4 September 2015; pp. 316-321.

8. Wolkiewicz, M.; Tarchała, G.; Orłowska-Kowalska, T.; Kowalski, C.T. Online Stator Interturn Short Circuits Monitoring in the DFOC Induction-Motor Drive. IEEE Trans. Ind. Electron. 2016, 63, 2517-2528. [CrossRef]

9. Drif, M.; Cardoso, A.J.M. Stator Fault Diagnostics in Squirrel Cage Three-Phase Induction Motor Drives Using the Instantaneous Active and Reactive Power Signature Analyses. IEEE Trans. Ind. Inform. 2014, 10, 1348-1360. [CrossRef] 
10. Skowron, M.; Orłowska-Kowalska, T.; Kowalski, C.T. Application of simplified convolutional neural networks for initial stator winding fault detection of the PMSM drive using different raw signal data. IET Electr. Power Appl. 2021, 15, 932-946. [CrossRef]

11. Usman, A.; Joshi, B.M.; Rajpurohit, B.S. Review of fault modeling methods for permanent magnet synchronous motors and their comparison. In Proceedings of the IEEE International Symposium on Diagnostics for Electric Machines, Power Electronics and Drives (SDEMPED), Tinos, Greece, 29 August-1 September 2017; pp. 141-146.

12. Rosero, J.; Romeral, L.; Rosero, E.; Urresty, J. Fault Detection in dynamic conditions by means of Discrete Wavelet Decomposition for PMSM running under Bearing Damage. In Proceedings of the Twenty-Fourth Annual IEEE Applied Power Electronics Conference and Exposition, Washington, DC, USA, 15-19 February 2009; pp. 951-956.

13. Krichen, M.; Elbouchikhi, E.; Benhadj, N.; Chaieb, M.; Benbouzid, M.; Neji, R. Motor Current Signature Analysis-Based Permanent Magnet Synchronous Motor Demagnetization Characterization and Detection. Machines 2020, 8, 35. [CrossRef]

14. Henao, H.; Capolino, G.A.; Fernandez-Cabanas, M.; Filippetti, F.; Bruzzese, C.; Strangas, E.; Pusca, R.; Estima, J.; Riera-Guasp, M.; Hedayati-kia, S. Trends in Fault Diagnosis for Electrical Machines. IEEE Ind. Electron. Mag. 2014, 8, 31-42. [CrossRef]

15. Antonino-Daviu, J.A.; Gyftakis, K.N.; Garcia-Hernandez, R.; Razik, H.; Marques Cardoso, A.J. Comparative influence of adjacent and non-adjacent broken rotor bars on the induction motor diagnosis through MCSA and ZSC methods. In Proceedings of the 41st IEEE Industrial Electronics Society (IECON), Yokohama, Japan, 9-12 November 2015; pp. 1680-1685.

16. Zidani, F.; Benbouzid, M.E.H.; Diallo, D.; Nait-Said, M.S. Induction motor stator faults diagnosis by a current Concordia pattern-based fuzzy decision system. IEEE Trans. Energy Convers. 2003, 18, 469-475. [CrossRef]

17. Jankowska, K.; Dybkowski, M. A Current Sensor Fault Tolerant Control Strategy for PMSM Drive Systems Based on $C_{\text {ri }}$ Markers. Energies 2021, 14, 3443. [CrossRef]

18. Chen, Y.; Liang, S.; Li, W.; Liang, H.; Wang, C. Faults and Diagnosis Methods of Permanent Magnet Synchronous Motors: A Review. Appl. Sci. 2019, 9, 2116. [CrossRef]

19. Kyeong-Hwa, K. Simple Online Fault Detecting Scheme for Short-Circuited Turn in a PMSM Through Current Harmonic Monitoring. IEEE Trans. Ind. Electron. 2011, 58, 2565-2568.

20. Wang, C.-S.; Kao, I.-H.; Perng, J.-W. Fault Diagnosis and Fault Frequency Determination of Permanent Magnet Synchronous Motor Based on Deep Learning. Sensors 2021, 21, 3608. [CrossRef]

21. Hang, H.; Ding, J.; Zhang, M.; Cheng, W.; Chen, W.; Wang, Q. Detection of Interturn Short-Circuit Fault for PMSM With Simple Fault Indicator. IEEE Trans. Energy Convers. 2016, 31, 1697-11699. [CrossRef]

22. Park, C.H.; Lee, J.; Ahn, G.; Youn, M.; Youn, B.D. Fault Detection of PMSM under Non-Stationary Conditions Based on Wavelet Transformation Combined with Distance Approach. In Proceedings of the IEEE International Symposium on Diagnostics for Electric Machines, Power Electronics and Drives (SDEMPED), Toulouse, France, 27-30 August 2019; pp. 88-93.

23. Ping, Z.A.; Juan, Y.; Ling, W. Fault Detection of Stator Winding Interturn Short Circuit in PMSM Based on Wavelet Packet Analysis. In Proceedings of the Fifth International Conference on Measuring Technology and Mechatronics Automation, Hong Kong, China, 16-17 January 2013; pp. 566-569.

24. Pietrzak, P.; Wolkiewicz, M. Comparison of Selected Methods for the Stator Winding Condition Monitoring of a PMSM Using the Stator Phase Currents. Energies 2021, 14, 1630. [CrossRef]

25. Hang, J.; Zhang, J.; Xia, M.; Ding, S.; Hua, W. Interturn Fault Diagnosis for Model-Predictive-Controlled-PMSM Based on Cost Function and Wavelet Transform. IEEE Trans. Power Electron. 2020, 35, 6405-6418. [CrossRef]

26. Maqsood, A.; Oslebo, D.; Corzine, K.; Parsa, L.; Ma, Y. STFT Cluster Analysis for DC Pulsed Load Monitoring and Fault Detection on Naval Shipboard Power Systems. IEEE Trans. Transp. Electrif. 2020, 6, 821-831. [CrossRef]

27. Wang, H.; Ji, Y. A Revised Hilbert-Huang Transform and Its Application to Fault Diagnosis in a Rotor System. Sensors 2018, 18, 4329. [CrossRef] [PubMed]

28. Rosero, J.; Ortega, J.; Urrest, J.; Cárdenas, J.; Romeral, L. Stator Short Circuits Detection in PMSM by means of Higher Order Spectral Analysis (HOSA). In Proceedings of the 24th Annual IEEE Applied Power Electronics Conference and Exposition, Piscataway, NJ, USA, 15-19 February 2009; pp. 964-969.

29. Ewert, P. The Application of the Bispectrum Analysis to Detect the Rotor Unbalance of the Induction Motor Supplied by the Mains and Frequency Converter. Energies 2020, 13, 3009. [CrossRef]

30. Kia, S.H.; Henao, H.; Capolino, G. A High-Resolution Frequency Estimation Method for Three-Phase Induction Machine Fault detection. IEEE Trans. Ind. Electron. 2007, 54, 2305-2314. [CrossRef]

31. Sun, L.; Xu, B. An Improved Method for Discerning Broken Rotor Bar Fault and Load Oscillation in Induction Motors. Energies 2018, 11, 3130. [CrossRef]

32. Trutt, F.C.; Sottile, K.; Kohler, J.L. Online condition monitoring of induction motors. IEEE Trans. Ind. Appl. 2002, 38, 1627-1632. [CrossRef]

33. Quiroga, J.; Liu, L.; Cartes, D.A. Fuzzy logic based fault detection of PMSM stator winding short under load fluctuation using negative sequence analysis. In Proceedings of the American Control Conference, Seattle, WA, USA, 11-13 June 2008; pp. 1627-1632. [CrossRef]

34. Ali, M.Z.; Shabbir, M.N.S.K.; Liang, X.; Zhang, Y.; Hu, T. Machine Learning-Based Fault Diagnosis for Single- and Multi-Faults in Induction Motors Using Measured Stator Currents and Vibration Signals. IEEE Trans. Ind. Appl. 2019, 55, 2378-2391. [CrossRef]

35. Ewert, P.; Orlowska-Kowalska, T.; Jankowska, K. Effectiveness Analysis of PMSM Motor Rolling Bearing Fault Detectors Based on Vibration Analysis and Shallow Neural Networks. Energies 2021, 14, 712. [CrossRef] 
36. Skowron, M.; Orłowska-Kowalska, T. Efficiency of Cascaded Neural Networks in Detecting Initial Damage to Induction Motor Electric Windings. Electronics 2020, 9, 1314. [CrossRef]

37. Lu, J.; Qian, W.; Li, S.; Cui, R. Enhanced K-Nearest Neighbor for Intelligent Fault Diagnosis of Rotating Machinery. Appl. Sci. 2021, 11, 919. [CrossRef]

38. Skowron, M.; Wolkiewicz, M.; Orlowska-Kowalska, T.; Kowalski, C.T. Effectiveness of Selected Neural Network Structures Based on Axial Flux Analysis in Stator and Rotor Winding Incipient Fault Detection of Inverter-fed Induction Motors. Energies 2019, 12, 2392. [CrossRef]

39. Chen, C.-C.; Liu, Z.; Yang, G.; Wu, C.-C.; Ye, Q. An Improved Fault Diagnosis Using 1D-Convolutional Neural Network Model. Electronics 2021, 10, 59. [CrossRef]

40. Yuan, H.; Wu, N.; Chen, X.; Wang, Y. Fault Diagnosis of Rolling Bearing Based on Shift Invariant Sparse Feature and Optimized Support Vector Machine. Machines 2021, 9, 98. [CrossRef]

41. Van, M.; Hoang, D.T.; Kang, H.J. Bearing Fault Diagnosis Using a Particle Swarm Optimization-Least Squares Wavelet Support Vector Machine Classifier. Sensors 2020, 20, 3422. [CrossRef]

42. Ince, T.; Kiranyaz, S.; Eren, L.; Askar, M.; Gabbouj, M. Real-time motor fault detection by 1-D convolutional neural networks. IEEE Trans. Ind. Electron. 2016, 63, 7067-7075. [CrossRef]

43. Bazan, G.H.; Goedtel, A.; Duque-Perez, O.; Morinigo-Sotelo, D. Multi-Fault Diagnosis in Three-Phase Induction Motors Using Data Optimization and Machine Learning Techniques. Electronics 2021, 10, 1462. [CrossRef]

44. Shifat, T.A.; Hur, J.-W. ANN assisted multi sensor information fusion for BLDC motor fault diagnosis. IEEE Access 2021, 9 , 9429-9441. [CrossRef]

45. Pietrzak, P.; Wolkiewicz, M. Application of Support Vector Machine to stator winding fault detection and classification of permanent magnet synchronous motor. In Proceedings of the 19th International Power Electronics and Motion Control Conference (PEMC), Gliwice, Poland, 25-29 April 2021; pp. 880-887. [CrossRef]

46. Xu, X.; Qiao, X.; Zhang, N.; Feng, J.; Wang, X. Review of intelligent fault diagnosis for permanent magnet synchronous motors in electric vehicles. Adv. Mech. Eng. 2020, 12,1-14. [CrossRef]

47. Cao, Q.; Gustozzi, F.; Zanni-Merk, C.; de Bertrand de Beuvron, F.; Reich, C. Smart Condition Monitoring for Industry 4.0 Manufacturing Processes: An Ontology-Based Approach. Cybern. Syst. 2019, 50, 82-96. [CrossRef]

48. Medina-García, J.; Sánchez-Rodríguez, T.; Galán, J.A.G.; Delgado, A.; Gómez-Bravo, F.; Jiménez, R. A Wireless Sensor System for Real-Time Monitoring and Fault Detection of Motor Arrays. Sensors 2017, 17, 469. [CrossRef]

49. Jiang, Y.; Yin, S.; Dong, J.; Kaynak, O. A Review on Soft Sensors for Monitoring, Control and Optimization of Industrial Processes. Cybern. Syst. 2019, 50, 12868-12881. [CrossRef]

50. Kumar, P.S.; Xie, L.; Halick, M.S.M.; Vaiyapuri, V. Stator End-Winding Thermal and Magnetic Sensor Arrays for Online Stator Inter-Turn Fault Detection. IEEE Sens. J. 2021, 21, 5312-5321. [CrossRef]

51. Samanta, S.; Bera, J.N.; Sarkar, G. KNN based fault diagnosis system for induction motor. In Proceedings of the 2nd International Conference on Control, Instrumentation, Energy \& Communication (CIEC), Kolkata, India, 28-30 January 2016; pp. 304-308. [CrossRef]

52. Ali, M.Z.; Shabbir, M.N.S.; Zaman, S.M.K.; Liang, X. Machine Learning Based Fault Diagnosis for Single-and Multi-Faults for Induction Motors Fed by Variable Frequency Drives. In Proceedings of the IEEE Industry Applications Society Annual Meeting, Baltimore, MD, USA, 29 September-3 October 2019; pp. 1-14. [CrossRef]

53. Surti, K.V.; Naik, C.A. Bearing Condition Monitoring of Induction Motor Based on Discrete Wavelet Transform \& K-nearest Neighbor. In Proceedings of the 3rd International Conference for Convergence in Technology (I2CT), Pune, India, 6-7 April 2018; pp. 1-5. [CrossRef]

54. Okfalisa; Gazalba, I.; Mustakim; Reza, N.G.I. Comparative analysis of k-nearest neighbor and modified k-nearest neighbor algorithm for data classification. In Proceedings of the 2nd International conferences on Information Technology, Information Systems and Electrical Engineering (ICITISEE), Yogyakarta, Indonesia, 1-3 November 2017; pp. 294-298. [CrossRef]

55. Wang, X.; Jiang, Z.; Yu, D. An Improved KNN Algorithm Based on Kernel Methods and Attribute Reduction. In Proceedings of the 5th International Conference on Instrumentation and Measurement, Computer, Communication and Control (IMCCC), Qinhuangdao, China, 18-20 September 2015; pp. 567-570. [CrossRef]

56. Hu, L.; Huang, M.W.; Ken, S.W.; Tsai, C.F. The distance function effect on k-nearest neighbor classification for medical datasets. SpringerPlus 2016, 5, 1304. [CrossRef]

57. Shifat, T.A.; Hur, J. An Improved Stator Winding Short-circuit Fault Diagnosis using AdaBoost Algorithm. In Proceedings of the International Conference on Artificial Intelligence in Information and Communication (ICAIIC), Fukuoka, Japan, 19-21 February 2020; pp. 382-387. [CrossRef]

58. Saadatfar, H.; Khosravi, S.; Joloudari, J.H.; Mosavi, A.; Shamshirband, S. A New K-Nearest Neighbors Classifier for Big Data Based on Efficient Data Pruning. Mathematics 2020, 8, 286. [CrossRef]

59. Ma, C.; Du, X.; Cao, L. Improved KNN Algorithm for Fine-Grained Classification of Encrypted Network Flow. Electronics 2020, 9, 324. [CrossRef]

60. Salvador-Meneses, J.; Ruiz-Chavez, Z.; Garcia-Rodriguez, J. Compressed kNN: K-Nearest Neighbors with Data Compression. Entropy 2019, 21, 234. [CrossRef] [PubMed] 
61. Irvani, M.R.; Karimi-Ghartemani, M. Online estimation of steady state and instantaneous symmetrical components. IET Proc. Gener. Transm. Distrib. 2003, 150, 616-622. [CrossRef]

62. Bajpai, D.; He, L. Evaluating KNN Performance on WESAD Dataset. In Proceedings of the 12th International Conference on Computational Intelligence and Communication Networks (CICN), Nainital, India, 25-26 September 2020; pp. 60-62. 